\title{
Cognitive Processes
}

\section{to Understand Alcohol Use Disorder}

Ph.D. Thesis

Adrienn Máttyássy M.D.

Doctoral School of Clinical Medicine

Department of Psychiatry, Bács-Kiskun County Hospital, Kecskemét

Supervisor:

Prof. Zoltán Janka M.D., Ph.D., D.Sc.

Oguz Kelemen M.D., Ph.D.

Szeged

2019 


\section{ORIGINAL RESEARCH ARTICLES RELATED ON THE THESIS}

I. Máttyássy A, Kéri S, Myers CE, Levy-Gigi E, Gluck MA, Kelemen O. (2012) Impaired generalization of associative learning in patients with alcohol dependence after intermediate-term abstinence. Alcohol Alcohol. 47(5):533-537.

\section{IF: 1.956}

II. Mátyássy A, Kelemen O, Sárközi Z, Janka Z, Kéri S. (2006) Recognition of complex mental states in patients with alcoholism after long-term abstinence. Alcohol Alcohol. 41(5):512-514.

\section{IF: 2.061}

\section{Cumulative impact factors: 4.017}

\section{SELECTED ABSTRACT RELATED TO THE THESIS}

I. Máttyássy A, Kéri S, Myers CE, Gluck MA, Kelemen O. (2011) Impaired generalization during reinforcement learning may indicate hippocampal dysfunctions in patients with alcoholism. (poster: P.6.a.001) ECNP Paris 2011. 10.06. (abstract: Eur Neuropsychopharmacol. 21, (Suppl. 3), p. S560).

\section{SELECTED PUBLICATIONS CLOSELY RELATED TO THE THESIS}

I. Máttyássy A. (2002) Farmakoterápia az addiktológiában. Családorvosi Fórum. 11:4-12.

II. Kelemen O, Máttyássy A, Kéri S. (2004) A ventromedialis prefrontalis kéreg szerepe addiktológiai kórképekben. Clin Neurosci. (Ideggy Szle.) 57:4-10.

III. Máttyássy A, Szücs A. (2005) Alkoholfüggőség - társuló hangulat - szorongásos zavarok. Addictol Hung. (Addiktológia) 4(3):297-318.

IV. Máttyássy A, Kelemen O. (2011) Az alkohol okozta mentális és viselkedési zavarok. In: A pszichiátria rövidített kézikönyve (szerk.: Németh A, Füredi J), pp. 187-212. Medicina, Budapest. 


\section{AbBreViations}

AA: Alcoholics Anonymous

ANOVA: analysis of variance

ASI: Addiction Severity Index

AUD: alcohol use disorder

BDI: Beck Depression Inventory

BG: basal ganglia

BPRS: Brief Psychiatric Rating Scale

DSM-IV: Diagnostic and Statistical Manual of Mental Disorders, 4th edition

DSM-5: Diagnostic and Statistical Manual of Mental Disorders, 5th edition

GAF: Global Assessment of Functioning Scale

MTL: middle temporal lobe

PFC: prefrontal cortex

PTSD: posttraumatic stress disorder

RDoC: Research Domain Criteria

RMET: Reading the Mind in the Eyes' Test /or Eyes Test

RAELT: Rutgers Acquired Equivalence Learning Test (Fish test)

pSTS: posterior superior temporal sulcus

SD: standard deviation

SUD: substance use disorder

STS: superior temporal sulcus

ToM: Theory of Mind

VTA: ventral tegmental area 


\section{TABLE OF CONTENTS}

1. Scope and aim of the study

2. Introduction 7

$\begin{array}{ll}\text { 2.1. General introduction } & 7\end{array}$

2.2. Cognitive dysfunctions in people suffering alcohol use disorder 9

2.2.1. Learning and memory 11

2.2.2. Social cognition 15

3. Questions addressed by the thesis 20

4. Subjects and methods $\quad 21$

4.1. Subjects 21

4.2. Procedures 23

4.2.1. Experiment 1: Investigating the associative learning process 23

4.2.2. Experiment 2: Investigating the "Theory of Mind" function 26

$\begin{array}{ll}\text { 5. Results } & 27\end{array}$

5.1. Experiment 1: Associative learning in alcohol use disorder 27

5.2. Experiment 2: "Theory of Mind" in alcohol use disorder 28

6. Discussion 30

7. General discussion 37

$\begin{array}{ll}\text { 7.1. Summary of the results } & 37\end{array}$

7.2. Cognitive impairment in alcohol use disorder 38

7.3. Implication for treatment of alcohol use disorder 39

7.4. Future direction $\quad 40$

8. Acknowledgements 41

9. References 42 


\section{SCOPE AND AIM OF THE STUDY}

Cognitive psychology created a useful viewpoint to comprehend psychiatric disorders. Among other conditions in the alcohol use disorder (AUD) it is also an important tool to understand the mechanism of dependencies and the underling brain networks. (Fein et al. 1990; Bernardin et al. 2014; Bickel et al. 2017; Loheswaran et al. 2016; van Holst and Schilt 2011). Discovering the neuronal foundation of this highly common disorder which causes significant social burden, promises the discovery of genetic etiology and could help to create proper pharmacological and psychological treatments (Marceau et al. 2017; Fein et al. 1990; Bernardin et al. 2014).

Then again, identifying brain processes and related cognitive dysfunctions increase vulnerability for AUD may provide us the possibility to recognize at an earlier stage and also could be critical in creating better prevention programs too. (Belin et al. 2015; Park et al. 2007).

Inspired by the forgoing issues, this thesis was intended to investigate cognitive processes in AUD. Long ago it was well known that alcohol is a neurotoxic agent that influences numerous cognitive processes, and these impaired brain functions show a gradual improvement correlated with the abstinence period after alcohol cessation (Fein et al. 1990; Crews and Nixon 2009). Therefore, to exclude the direct toxic effect and allow a longer regeneration period in our research we have investigated patients after at least 6 months of abstinence focusing in particular on memory functions and mentalization processes.

The main goals of this work were to investigate the following:

I. To examine the associative learning functions in intermediate-term abstinent alcohol dependence patients

II. To assess the social cognitive functions using tests to investigate complex emotional recognition in intermediate-term abstinent alcohol dependence patients 
Examining the first aim we surveyed associative learning and found that while the patients demonstrated normal function in the basal ganglia-dependent acquisition phase, there was an impairment in the temporal lobe-dependent process during the transfer phase. Studying the second question we have found that the representation of mental states of others ("Theory of Mind" (ToM)) was saved in AUD.

These results suggest that abstinent patients with AUD show marked dysfunctions in the generalization of association, which may indicate the dysfunction of the medial temporal lobe. On the other hand, neither the basal ganglia-dependent learning, nor the social cognitive functions demonstrated significant impairment after longer (intermediate-term) abstinence. 


\section{INTRODUCTION}

\subsection{GENERAL INTRODUCTION}

Alcohol use disorder (AUD) is one of the most concerning problems of health related behaviour resulting in diverse mental and somatic consequences (neuropsychiatric disorders $39 \%$, traumatic injuries, hepatological disorders 9.6\%, cancers $8.1 \%$ (Rehm et al. 2010; Lachenmeier et al. 2011). According to the WHO statistic data from 2012, 3.3 million deaths (meaning $5.9 \%$ of all global deaths) were related to alcohol misuse (WHO, 2014). In the USA $6.2 \%$ of the adult population (i.e. 15.1 million adults) had AUD according to the National Survey on Drug Use and Health in 2015 (Substance Abuse and Mental Health Services Administration (SAMHSA) 2015)) and the resulting economic burden caused by alcohol misuse is huge (USA, 2010: \$249.0 billion (Sacks et al. 2015.)). In Hungary the issue is even more grievous, and our statistical data shows massive problem in this area. According to the WHO survey the prevalence of alcohol use disorder was 17.7\% (or alcohol dependence 9.4\%) in 2010, which was more than double that of the USA's statistics (USA: 7.4\%, 4.7\%), and was comparable to the Russian percentage (Russia: 17.4\%, 9.3\%, respectively) (WHO 2014).

From the medical point of view, AUD is a complex mental disorder with many comorbidities and different aetiologies. Obviously the genetic background is an important factor. According to current estimates, the heritability of AUD is about 50\% (Verhulst et al. 2015). Other biological factors may overlap, such as nutrition (poor diet, and vitamin deficiency) which is a common problem among heavy drinkers (Butterworth 1995). The psychological theories describe some personality traits (e.g. impulsivity, risk taking behaviour) that predispose for AUD, and also emphasize the anxiolytic and relaxant effects of alcohol, suggesting that alcohol can be for many the mechanism to cope with everyday stress. From the perspective of behavioural psychology, alcohol has a huge 'rewarding potential' (probably through the mesolimbic dopamine reward system) and it creates a growing crave if missed. We should consider that alcohol dependence develops over a long period, so the duration of alcohol misuse also causes ever increasing impairment of brain function. The factors important in the initiation of alcohol use and misuse also emphasize many social and religious/spiritual components as well (Frings et al. 2018). Connected to the etiological 
factors, the psychological impairment caused by the long term alcohol use, and the biological and psychosocial consequences of AUD make regeneration and rehabilitation even more complicated. These factors influence each other in such as complex many as to create a classical circular causality. It is clear for now that proper treatment needs a complex approach to break this vicious circle, so pharmacotherapy primarily for diminishing the neural circuits related to craving, or the treatment of co-morbidities forces us to the abyss of alcohol. Psychological techniques such as motivational interviews can enhance inner motivations toward any required change in behaviours. Psychotherapies such as behavioural and cognitive therapies focus on the stimuli and schemas associated with relapse and craving. Family interventions examine and change system framework elements and dynamics within the family. Alcoholic Anonymous (AA) building on the 12 steps program or other professional and self-help groups can incorporate spiritual sources and use social support to the treatment process as well (Carrico et al. 2007).

Cognitive psychology represents an extremely useful approach for understanding clinical psychiatric conditions. Before all, the cognitive impairments can represent an endophenotype (intermediate phenotype) which connects clinical symptoms to basic biological (neural networks) or genetic findings (Gottesman and Gould 2003; Gould and Gottesman 2006). On the other hand, alcohol itself can change the functional connections of the brain and can cause direct neuronal damage resulting in cognitive dysfunctions. Even acute abuse of alcohol causes some reversible dose dependent mental disequilibrium (McKinney and Coyle 2004; Prat et al. 2008; Ling et al. 2010). Long-term alcohol use develops permanent damage, sometimes as extreme as Korsakoff syndrome or alcoholinduced dementia (Martin et al. 1986). Although alcohol causes diffuse brain deterioration, some brain areas seem markedly sensitive for it, such as the limbic system (especially amygdala and hippocampus), diencephalon, prefrontal cortex and the cerebellum (OscarBerman et al. 1997; Chanraud and Sullivan 2014). The damage of these brain areas necessarily develops functional impairments as well, which can be detected by employing cognitive psychological tasks. Fortunately, after discontinuation of alcohol abuse a gradual cognitive recovery can be seen. 


\subsection{COGNITIVE DYSFUNCTIONS IN PEOPLE SUFFERING ALCOHOL USE DISORDER}

The early conclusion of Fein et al. (1990) tried to synthetize the data in terms of the duration of abstinence. They distinguished three periods: (i) acute detoxification (up to 2 weeks of abstinence), (ii) intermediate period (3 months of abstinence) and (iii) long-term abstinence (from 2 months to 5 years). (At present the official terminology in the literature uses a slightly different division: short-term abstinence means less than 1 month, intermediate means 2-12 months, long-term abstinence means more than a year.) Alcohol acute intoxication has well-known deleterious impact on cognition even for non-alcoholic persons. For this reason, the neuropsychological assessment before detoxification is either unreal or unreasonable. During "the intermediate term abstinence" the average IQ test scores are mainly normalized, but for many patients the fluid intelligence skills are still impaired. In their summary many cognitive functions improved relatively early in areas such as attention and concentration, reaction time, verbal learning, abstract reasoning and verbal short-term memory, but others, especially abstract reasoning, visuospatial ability, short-term memory and mental flexibility remained affected even after long-term sobriety (Fein et al. 1990). In their research Andó et al. (2012) used a gambling test in an AUD patient with long-term abstinence, and found persisting decision making deficit. The slow rehabilitation process was further underscored by the fact that in certain studies even after several years of abstinence some cognitive impairments could be observed; as with the Fein et al. (2006) study (average abstinence time: 6.7 years) where spatial processing was still impaired or in the Brandt et al. (1983) report where new verbal associations learning was impaired for a long time after discontinuing alcohol usage.

Despite the wide variety of psychological functions investigated in earlier studies, most of the papers subsequently focused on more specific neurocognitive impairments. Overall they highlight the executive function, memory impairment at the top of the list, but visuospatial functions are also repeatedly supported (Oscar-Berman and Marinkovic 2007; Fernández-Serrano et al. 2010; Bernardin et al. 2014; Le Berre et al. 2017). Here we would focus on the results related to the executive and memory functions.

It should be remembered that the executive function is an umbrella term, and contains many cognitive processes that take part in the control and construction of behaviour. Cognitive flexibility, and on a higher level even problem-solving, decision making, and 
planning functions are discussed within this term. Some methods developed for investigating attention and working memory processes are also applied in executing function research; all serving to highlight the overlap within the terminology used (Pitel et al. 2014).

Considering the whole spectrum of addictive disorders, Fernández-Serrano et al. (2010) found different patterns of impaired execution functions among different substance users, and identified that alcohol especially damages the decision making process and the verbal fluency function (verbal fluency is also considered as working memory or sematic memory task!). van Holst and Schilt (2011) also reviewed neuropsychological profiles of the substance use disorder (SUD). For alcohol dependent people (after a minimum 2 weeks of abstinence; average 32 weeks) the most prominent finding was the impairment in working memory and visuospatial functions, while opiate dependency was associated with severe verbal fluency impairment, and cocaine and (meth)amphetamines were correlated with poor cognitive planning and flexibility.

The interaction of the executive, working memory system with the classical long-term memory systems is so logical that it raises the question as to whether the impairments in them exist separately at all. Bernardin et al. (2014) mention that memory dysfunction manifested in AUD should be interrelated to executive functions findings, but there must be a genuine episodic memory deficit as well (the same finding in Pitel et al. 2007). In their summary (Bernardin et al. 2014) they state that a longer period of abstinence (several months) correlates directly to a greater brain recovery, and usually needs more than a year to manifest as normal in the overall cognitive profile. Some mild visuospatial impairments can still be evident even after several years of abstinence.

It is important to remark that among young adults even low level but regular alcohol intake can decrease the executive functions (Hatchhard et al. 2015). 


\subsubsection{LEARNING AND MEMORY}

Beside other neurocognitive damage, deterioration of the long-term memory processes is one of the most consistently reported impairment in AUD. It has been clear for a long time, that chronic alcohol use can cause severe impairment in the memory system and develop such disorders as alcohol related dementia or Korsakoff syndrome. For developing special, sophisticated therapies, earlier stage recognition is needed, and subtle impairments need to be detected.

Contemporary research conducted on both humans and animals indicated that multiple interacting but dissociable memory systems exist in the brain. The basic distinction for longterm memory refers to implicit (procedural) and explicit (declarative) (Zola-Morgan and Squire 1993; Gabrieli 1998; Ashby et al. 1998; Kéri 2003; Poldrack and Packard 2003).

Explicit ("declarative or overt") memory refers to conscious recollection of facts and events. It is further classified into semantic and episodic subdivisions. Semantic memory is identified as concept-based meaning and context independent categories. Episodic memory is related to specific personal experiences, so it is evidently context dependent, and even the source of the memory trace is included within it. On the other hand, the contents of implicit ("procedural or covert") memory are inaccessible for conscious information processing. Learning lists of words or face-name associations are classic examples for explicit memory, whereas gaining sensory-motor skills and stimulus-response patterns (multi-step "towertype" tests, mirror drawing, and pursuit rotor tasks) are subjects of implicit memory. The medio-temporal (hippocampal) and diencephalic structures are candidate neuronal substrates for explicit memory. Implicit memory includes many diverse processes contained within different brain areas such as the sensory neocortex, basal ganglia, and cerebellum. Animal and human data supports the fact that the basal ganglia play a crucial role for gradual learning skills and habits (Schacter et al. 2000; Squire 2004) and in addictions it is responsible for the development of reward dependent drug-seeking habits (Koob and Volkow 2016). Beside the classical stimulus response associative learning, the basal ganglia are crucial in sequence learning and category learning as well (Yin and Knowlton 2006; Graybiel 2008). The interaction of the two systems is critical, so although the medial temporal lobe is not directly associated with stimulus-response learning, it has a major role in the generalization of previously learned information in a novel context (Manns and Eichenbaum 2006). 
Because explicit memory is more perceived it is obvious that there is a larger body of work and research available in the investigation of this area in AUD. In case of semantic tasks, AUD patients have diminished capacity in being able to encode novel facts (Pitel et al. 2014). Interestingly they have a tendency to use a higher level of compensatory strategies to solve simple tasks (Chanraud et al. 2013). Additionally, many studies highlighted a considerable slower learning processes and a specific vulnerability of the episodic memory subsystem, either in encoding or retrieval processes (Pitel et al. 2014; Németh et al. 2014). Alcoholic persons also show a kind of insight bias in overestimating their episodic memory performance (Le Berre et al. 2010). Recently Nandrino et al. (2016) found that even after longer periods of sobriety (min. 6 months) both the semantic and the episodic component of the autobiographical memory were impaired. This disruption was more severe in the memory related to the recent past, which may be due to the direct effect of alcohol on encoding and consolidation processes. In relation to the psychological data available, many imaging data sets support the concept of severe damage of the MTL and related areas in this population (Oscar-Berman and Marinkovic 2003; Beresford et al. 2006; Pitel et al. 2014; Pfefferbaum et al. 2009; Schulte et al 2010).

In case of implicit learning processes early studies used paradigms from social psychology which focus on the expectancies and attitudes (e.g. Implicit Association Test, or Extrinsic Affective Simon Task) (Reich et al. 2010). Others emphasize implicit associations causing priming effect (Roehrich and Goldman 1995; Weingardt et al. 1996; Ames and Stacy 1998) which may be important in craving. Both approaches tried to investigate the distortion or the specialties rather than the extent of the impairment of implicit processes in AUD (Wiers et al. 2002).

Implicit perceptual learning (visuoperceptual priming) was also investigated but it was found that the posterior cerebral areas were relatively intact even in Korsakoff syndrome patients (Fama et al. 2006, Oudman et al. 2011).

Duka et al. (2001) applied a world pairs test and a stem completion part which contains an implicit and explicit element. They found that after acute alcohol administration the participant had dose-dependent difficulties to complete the explicit part correctly; while no impairment was detected in the implicit part. 
However, there are limited results available to special BG related test functions in human studies, although according to animal studies this cortico-basal ganglia-cortical loop plays a pivotal role in reward and reinforced learning and Pavlovian conditioning are crucial in the development of dependency (Koob and Volkow 2016; Lovinger and Alvarez 2017).

An interesting study investigated the implicit sequence learning and the PFC functions (Virág et al. 2015). They used the alternating serial reaction time task, the so called "catch the dog" test for measuring implicit learning processes, and different working memory tests such as the digit span, listening span, counting span, and the letter fluency tasks. The value of this study is that they move forward from the acute effects of alcohol and choose a patient population who had been sober for at least 3 weeks. Their results showed intact implicit functions, but impaired PFC dependent working memory processes.

However, even long after this study there have been no published work that specifically investigated BG and MTL dependent learning within the same task in AUD. This is important because basic differences among the tests for implicit and explicit memory systems could result questionable findings. For this reason, we had chosen a single test, the so called acquired equivalence learning test (RAELT: Rutgers Acquired Equivalence Learning Test) to investigate the possible memory impairment in AUD. The RAELT (Myers et al. 2003) offers an exclusive chance to compare BG and MTL dependent learning within one task. The paradigm used in this test is based on a large body of evidence from animal and clinical research, postulating that plain stimulus response learning and the generalization of it are based on the mutual BG and the MTL functions (Mishkin et al. 1984; Packard and Knowlton 2002; Myers et al. 2002, 2003; Kéri 2003). In the first phase (acquisition phase, training phase) participants learn stimulus-response associations (faces-fishes), which are related to BG functions. In the second, also called transfer phase, we investigate how they can generalize the acquired learning pattern, which requires the use of MTL related processes (Mishkin et al. 1984; Packard and Knowlton 2002; Myers et al. 2002, 2003; Kéri 2003).

The utility of this test is supported by the double dissociation paradigm and imaging data (Moustafa et al. 2010: Table 1 is an extended version of the original table in Moustafa et al. 2010 with permission). The primarily basal ganglia affected Parkinson's disease patients showed weaker stimulus and stimulus associative learning, but they could solve the transfer phase of this test (Myers et al. 2003). In contrast, patients with early stage hippocampal impairment, such as patients with Alzheimer's disease or with schizophrenia, demonstrated 
proper learning in the associative learning phase, but severe impairment in generalization and acquired equivalence (Myers et al. 2003; Kéri et al. 2005; Bódi et al. 2009). Imaging studies using the corresponding acquired equivalence task setting found favourable response to the substantia nigra (VTA) activation related to the reward guided learning situation, and the hippocampal region activation in the generalization phase, although they emphasize that generalization starts within the encoding period (not only in the retrieval process) causing a coupled change during acquisition phase activity in the hippocampus and midbrain (Shohamy and Wagner 2008; Berens and Bird 2017).

Increased performance in generalization process was also found in PTSD patients with re-experiencing symptoms. This result pre-supposes that the hyper-generalization process of the hippocampus is not related merely to traumatic memories and situations in PTSD (Kostek et al. 2014; Levy-Gigi et al. 2015).

Table 1. Rutgers Acquired Equivalence Learning Test impairments in different neuropsychiatric disorders

\begin{tabular}{|l|l|l|l|}
\hline Disorder & Article & Acquisition & Transfer \\
\hline Parkinson's disease (medicated) & Myers et al. 2003 & $\downarrow$ & - \\
\hline $\begin{array}{l}\text { ACoA aneurysm (Basal forebrain } \\
\text { amnesia) }\end{array}$ & Myers et al. 2008 & $\downarrow$ & - \\
\hline Schizophrenia & Kéri et al. 2005 & - & $\downarrow$ \\
\hline $\begin{array}{l}\text { Hippocampal atrophy /Hypoxic/ } \\
\text { mild Alzheimer's }\end{array}$ & $\begin{array}{l}\text { Bódi et al. 2009 } \\
\text { Myers et al. 2003, 2008 }\end{array}$ & - & $\downarrow$ \\
\hline PTSD & $\begin{array}{l}\text { Khalil et al. 2015 } \\
\text { Levy-Gigi et al. 2015 }\end{array}$ & - & $\uparrow$ \\
\hline Cocaine & Vadhan et al. 2008 & $\downarrow$ & - \\
\hline Opiate & Myers et al. 2017 & $\downarrow$ & - \\
\hline
\end{tabular}

(Extended version of the original table in Moustafa et al. 2010 with permission)

Vadhan et al. (2008) investigated 22 active cocaine users (min. 2 days/week; majority polydrug user: 17 of them also reported current alcohol use and 7 of them current marijuana use). Employing the same task (RAELT), in the late stage of the acquisition phase cocaine users committed significantly more errors, but there was no impairment during the transfer phase, so generalization was intact. This finding resembles the pattern of impairment detected 
in Parkinson's disease (although at a moderate level), and could be rationalized by the fact that cocaine can modulate the dopamine interconnections between the BG subregions.

Recently the updated variant of the acquired equivalence task was applied in opiatedependent patients (Myers et al. 2017). This version of the study was designed to discriminate between the reward-based and the punishment-based training processes. Thirty-three opioiddependent patients participating in methadone maintenance treatment were also recruited. Past and present secondary drug use was not an exclusion criterion (many of them also reported cigarette use, mild alcohol use (2 of them heavy alcohol use), and marijuana use). A number of them also reported past use of illicit psychostimulants. As in the case of cocaine addicted patients during the transfer phase they did not display impaired performance. Nevertheless, the training phase performance was divided. There was no difference on reward-based learning, while on punishment-based learning situations, especially during the final stage they demonstrated a much slower learning capacity. In respect to our own research we should emphasize that this study found a BG related memory dysfunction with opiate-dependent patients (Table 1).

\subsubsection{SOCIAL COGNITION}

"Theory of Mind" (ToM) refers to a possibly unique human ability to attribute beliefs, intentions, and feelings to other persons (Frith and Frith 1999). There are several synonyms for ToM in the scientific literature such as "mentalizing" (Frith et al. 1991), "mind reading", and "social intelligence" (Baron-Cohen et al. 2001). Recent research has demonstrated that ToM can be dissociated from other cognitive functions and is related to a relatively specialized social cognitive network in the brain, including the medial prefrontal and cingulate cortex, posterior superior temporal cortex, and temporal pole (Gallagher and Frith 2003; Fine et al. 2001; Rajkumar et. al. 2008). Perhaps not surprisingly some other findings emphasize the interaction between ToM functions and the executive functions (Bull et al. 2008), or even the explicit memory systems (Nandrino et al 2014). The contradictory finding corroborates the need of standard methodology. There are many types of tasks measuring ToM. Some of them include interactive games: like stone-paper-scissor game which should activate supreme ToM processes. Others use verbal stories that require the attribution of mental states of protagonists: faux pas task, or stories including irony, and metaphors are common examples thereof. Comic-strips of short stories with characters who have different 
beliefs are especially convenient for children who perhaps have not developed reading skills. Most of these tests operate with, and require the ability to decode contextual information. These kind of processes are described as ToM Reasoning functions, and also referred to as cognitive or "cold" ToM.

Finally, mental states can be read from faces and eyes expressions. The Reading the Mind in the Eyes' Test (RMET) use fragments of facial expressions of mental states (not mere basic emotions but complex mental status as well) just the part of the face around the eyes. Here obviously the subjects need to recognize the complex mental state from the picture but this test latently supposes proper use of the semantical knowledge of these mental states. This is an automatic, unconscious evaluation without any major learning tendencies. Apparently this test focuses on the relevant mental state (e.g. sarcastic, fearful), and excludes environmental information (Baron-Cohen et al. 2001), which makes this test more independent from contextual factors. These kind of tests require an affective or "hot" mentalizing process. It should be taken into consideration that this test contains pictures of Caucasian population, so cultural independency could be questioned, but in our region and our sample, this possible complication was not an issue.

It is assumed that the neural base of ToM consists a complex brain network within the prefrontal (PFC) and the temporal cortical connections are also essential (Gallagher and Frith 2003; Uekermann and Daum 2008; Molenberghs et al. 2016). Although there is a huge overlapping brain network necessary for any kind of ToM test (Molenberghs et al. 2016), the dIPFC related processes are crucial, especially for the cognitive/"cold" type of ToM (ShamayTsoory and Aharon-Peretz 2007; Shamay-Tsoory et al. 2009; Poletti et al. 2012). The affective/"hot" ToM is rather connected to the orbitofrontal and the vmPFC regions (ShamayTsoory and Aharon-Peretz 2007; Shamay-Tsoory et al. 2009; Poletti et al. 2012). If we specifically focus on the RMET test, brain imaging studies affirm the importance of the posterior superior temporal sulcus (pSTS) and the inferior frontal gyrus (Baron-Cohen et al. 1999; Overgaauw 2015; Yang 2015).

Our choice to use the RMET test is based on the feasibility and the contextual free design of this. Also an important factor was that this task is widely used in the psychiatric literature for measuring ToM deficits. 
Because psychiatric conditions severely influence social functions and integration, the investigations of the ToM processes occupy a central position in the last few decades of psychiatric research.

Patients with schizophrenia demonstrate wider areas of social cognitive impairments, including perception of basic emotions and social cues, as well as severe dysfunctions in everyday social skills (Penn et al. 1997). Results obtained with ToM tests have consistently been shown to be impaired in patients with schizophrenia (Mondragón-Maya et al 2017; Healey et al. 2016), and also in some neurodevelopmental disorders starting in childhood like autism-spectrum disorders, or in attention deficit hyperactivity disorder (Baron-Cohen et al. 2001; Korkmaz 2011; Pelphrey et al. 2011; Bora and Pantelis 2016a). Additionally, a growing body of literature confers the social cognitive functions in mood disorders (Samamé et al. 2012; Bora and Berk 2016; Bora et al. 2016; Bora and Pantelis 2016b). In recent reviews it is summarised that significant but modest degree of ToM dysfunction is evident in remitted and subsyndromal bipolar disorder, which is less severe than in schizophrenia (Bora and Pantelis 2016b). However, the difference is moderate and there is a remarkable overlap between the two groups. In unipolar depression the facial emotion recognition test has been used for a long time, and it was found that there is a mild loss in recognition of basic emotions (Dalili et al. 2015). At more complex levels modest impairment was detected in ToM functions and this was correlated with the severity of the symptoms of the mood disorder (Bora and Berk 2016).

There is an increasing literature supporting the fact that social cognition impairment is present in patients with different SUD (Peters et al. 2008; Sanvicente-Vieira et al. 2017a, 2017b).

As a precondition of social functions some investigations focus on the recognition of the basic emotions. A recent review of a selected 26 studies surmises that only a tendency toward an impairment in AUD can be detected. However, specific emphasis was placed upon the recognition of disgust and sadness (Donadon and Osório 2014). In the cases where the response latency was measured, they found a slower emotion recognition in AUD. The summary concludes that the data are controversial, as sample taking was not even and heterogeneity of the studies is very limited (57.7\% of them was done in Belgium). From a methodical standpoint very few studies use proper clinical interviews to rule out other comorbid conditions, and the abstinent period was relatively short (most of the participants 
were inpatients $(80.8 \%)$, and the average abstinent period was 3 weeks (1-8 weeks)). A few studies have investigated the effect of abstinence on emotion recognitions and have found that patients with a midterm (2-3 months) abstinence could evaluate the intensity of the emotion more correctly (Kornreich et al. 2001; Foisy et al. 2007). However, impairment in recognition accuracy, especially for anger and disgust, was still detectable. It is interesting that recently detoxified patients even have a tendency to overestimate the intensity of some basic emotions.

Compared to other SUD patients, especially patients with opiate dependence (Kornreich et al. 2003) it was found that emotion recognition deficit was more severe in patients with alcoholism.

Bora and Zorlu (2017) in their meta-analysis evaluated the studies dealing with both the basic facial emotion recognition and the higher level ToM functions. They confirmed the findings of Donadon and Osório (2014) regarding facial recognition impairment in AUD, but they calculated a more notable effect in case of disgust (effect size: $d=0.62$ ) and anger ( $d=0.47)$. In relation to ToM functions they included in their research both types of studies which employ either ToM decoding (RMET) or ToM reasoning (such as faux pas) tests. Their results show that ToM is significantly compromised in AUD $(\mathrm{d}=0.58)$. They also emphasize that longer duration of alcohol consumption and more severe depressive symptoms correlate with poorer performance.

Earlier, Onuoha et al. (2016) in a meta-analysis (first in the field) focused specifically on the ToM functions in AUD. As in the paper of Bora and Zorlu (2017), the great majority of the available articles used the RMET test, suggesting RMET as a sensitive tool for research purposes in this area, and also recommended the usage of it in AUD. Their conclusion was that lower mentalization performance is noticeable (with large effect size: Hedges' g was $1.62[(-2.28,-0.96), \mathrm{SE}=0.66, \mathrm{P}<0.01])$ in AUD.

It has been proposed that facial emotion in decoding problems could be present before the development of addiction (Hill et al. 2007; Kopera et al. 2014; Hulvershorn et al. 2013) and chronic alcohol consumption may have an additional detrimental effect on the decoding of social signals. If the mentalization process is impaired even before the manifestation of AUD, it could be a trait marker or even a risk factor, causing disturbed interpersonal relationships leading to social embarrassment, and alcohol use could be considered as a kind of "self-help treatment strategy" to decrease this frustration. This hypothesis is supported by the data that 
other SUD disorders and even addictive behaviours such as gambling are associated with social cognitive impairment (Kornreich et al. 2003; Peters et al. 2008; Sanvicente-Vieira et al. 2017a, 2017b; Kornreich et al. 2016).

Even if the deterioration is a consequence of the substance use, the clinical significance of it is huge because the altered social cognitive functions may contribute to the community adaptation failure of many patients, aggravating the patient-physician communication and subsequent social rehabilitation as well. 


\section{QUESTIONS ADDRESSED BY THE THESIS}

The thesis addressed the following research questions:

1. Is the basal ganglia-dependent learning process affected in AUD after longer periods of (intermediate-term) abstinence? (Experiment 1; paper I)

2. Is medial temporal lobe-dependent learning impaired after a longer period of abstinence? (Experiment 1; paper I)

3. Is there a correlation between explicit and implicit memory systems? (Experiment 1; paper I)

4. Is there a ToM deficit in AUD after a longer period of abstinence? (Experiment 2; paper II) 


\section{SUBJECTS AND METHODS}

From an ethical perspective all participants received sufficient information concerning the procedure prior to the commencement of the study, and all signed a formal written consent. The patient groups were recruited from the local Alcoholic Anonymous (AA) service. They did not belong to our department so cooperation was absolutely voluntary, and anyone could quit the participation any time (without any possible constraint). Before any further assessment the exclusion and inclusion criteria were examined by trained professionals specialized in psychiatry.

We had the permission of the local Ethics Committee in each study.

\subsection{SUBJECTS}

The patient group consisted of 20 subjects in Experiment 1 (Associative Learning: Fish) and 30 subjects in Experiment 2 (ToM: RMET) with DSM-IV alcohol dependence (American Psychiatric Association 1994) participating in Alcoholic Anonymous (AA) groups. In the first place the inclusion criteria included abstinence for more than 6 months (average: 9.8 months, $\mathrm{SD}=3.1$ ) to investigate the regeneration of neural functions. We also used the revised version of the Wechsler Intelligence Scale to assess the general cognitive functions (Wechsler 1981). Exclusion criteria contained any neuropsychiatric disorder besides AUD and was assessed with the MINI International Neuropsychiatric Interview Plus (Sheehan et al. 1998; Balázs and Bitter 2000). Individuals with concurrent DSM-IV Axis I disorders, history of brain injury, neurological disorders, drug abuse and dependence, and delirium were ineligible to participate in the study. The patients did not receive any psychotropic drugs. To exclude unexplored depression symptoms that may have influenced cognitive functions we used a limit score of $<10$ on the Beck Depression Inventory (BDI) (Beck 1987). None of the patients showed any sign of alcohol intoxication and relapse. Patients were evaluated with the Addiction Severity Index (ASI) semi-structured interview (McLellan et al. 1980). General psychosocial functions were assessed with the Global Assessment of Functioning (GAF) scale (American Psychiatric Association 1994). 
The control persons were volunteers matched for number, age, education, and intelligence quotient (IQ), BDI and GAF scores. The control volunteers were also screened with the MINI International Neuropsychiatric Interview Plus (Sheehan et al. 1998; Balázs and Bitter 2000) in order to exclude Axis I mental disorders and drug abuse/dependence. They were social drinkers and scored zero on the CAGE questionnaire (Ewing 1984). After being given a description of the study, participants were asked to give their consent. All subjects gave their informed consent. (Table 2. describes the characteristics of the participants.)

Table 2. Demographic and illness-related characteristics of the participants

\begin{tabular}{|c|c|c|c|}
\hline & $\begin{array}{r}\text { ALC Fish } \\
(\mathrm{n}=20)\end{array}$ & $\begin{array}{r}\text { ALC Eyes } \\
(\mathrm{n}=30)\end{array}$ & HC 20/30 \\
\hline Age (years) & $37.2(11.5)$ & $37.6(11.7)$ & $36.3(10.1)$ \\
\hline Gender : Male/Female & & $\mathrm{M}: 18 / \mathrm{F}: 12$ & \\
\hline Education (years) & $12.2(3.3)$ & $12.1(3.2)$ & $11.4(3.8)$ \\
\hline Wechsler Adult Intelligence Scale & $\begin{array}{r}109.2 \\
(10.8)\end{array}$ & $108.5(10.9$ & $112.7(14.2)$ \\
\hline GAF & $71.2(14.8)$ & $71.1(14.6)$ & $74.4(10.7)$ \\
\hline BDI & $7.8(2.3)$ & & $7.4(2.1)$ \\
\hline ASI severity profile: personal health: medical & $2.8(1.4)$ & $0.11(0.24)$ & 0 \\
\hline ASI severity profile: personal health: psychiatric & $1.1(0.5)$ & $0.12(0.30)$ & \\
\hline ASI severity profile: social functioning: employment & $3.4(1.2)$ & $0.42(0.53)$ & \\
\hline ASI severity profile: social functioning: family/social & $3.2(1.4)$ & $0.09(0.15)$ & \\
\hline ASI severity profile: social functioning: legal & $1.2(0.4)$ & $0.10(0.12)$ & \\
\hline \multicolumn{4}{|c|}{ Alcohol-related characteristic of addicted population (from ASI) } \\
\hline Age started drinking - alcohol any use at all & $15.3(3.7)$ & & \\
\hline Age at first heavy use - alcohol to intoxication & $23.4(4.1)$ & & \\
\hline Hospitalized due to alcohol withdrawal & $4.2(3.1)$ & & \\
\hline Ambulate alcohol detoxification & $4.2(3.9)$ & & \\
\hline Duration of abstinence (month) & $9.8(3.1)$ & & \\
\hline ASI severity profile: alcohol use (at present) & $0.0(0.0)$ & & \\
\hline ASI severity profile: substance use (at present) & $0.0(0.0)$ & & \\
\hline Duration of illness (years) & & $6.2(4.5)$ & \\
\hline
\end{tabular}

Data-sets are shown as mean (SD). ASI, Addiction Severity index composite scores, past 30-day data before the onset of abstinence period; Student's t-tests revealed no significant differences for these measures $(\mathrm{P}>0.2)$.

Patients and controls did not differ in paired measures $(\mathrm{P}>0.1, \mathrm{t}$ tests $)$. 


\subsection{Procedures}

\subsubsection{EXPERIMENT 1: INVESTIGATING THE ASSOCIATIVE LEARNING PROCESS}

The acquired equivalence associative learning task

Stimuli were presented and responses were gathered, using a Macintosh Power-Book laptop. The antecedent stimuli were four illustrations of faces (man, woman, girl and boy). The boy and woman had blond hair while the girl and man had dark hair. Thus, each stimulus had three possible pairs related to 1) age (adult vs. child), 2) gender (male vs. female) and 3) hair colour (blond vs. dark). The consequent images were cartoons of fishes coloured red, orange, pink and purple. Two fishes appeared under the faces, but the position (left-right) randomly varied in each trial. For each participant the different faces and the coloured fish were randomly designated to antecedent and consequent stimuli by the computer. The antecedents and consequents both were presented about 1-inch-tall on the screen.

At the beginning of the experiment, the following directions were shown on the screen: 'Welcome to the experiment. You will see drawings of people who each have some pet fish. Different people have different kinds of fish. Your job is to learn which kind of fish each person has. At first, you will have to guess.' On every trial, a face and two fish drawings appeared on the computer screen along with the prompt: 'Which fish does this person have? Use the Left or Right key to choose.' The participant should press one of two separate keys labelled as 'LEFT' and 'RIGHT' to mark whether the fish on the left or the fish on the right was associated with the face. The chosen fish drawing was encircled and confirming feedback was given (Figure 1). When an incorrect response was given a sharp, alert beep sounded (Figure 2). The left-right ordering of the fish drawings was randomized across subjects. 
A

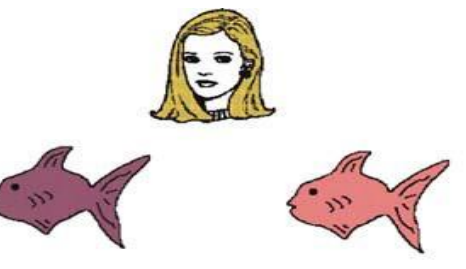

Which fish does this person have? Use "Left" or "Right" key to choose.

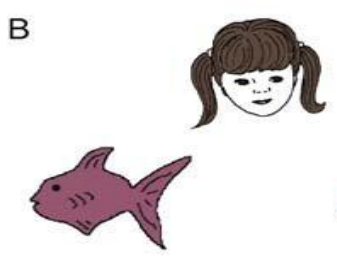

Which fish does this person have? Use "Left" or "Right" key to choose.

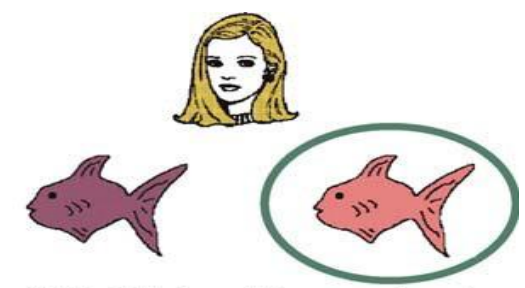

Which fish does this person have? Use "Left" or "Right" key to choose. Correct!

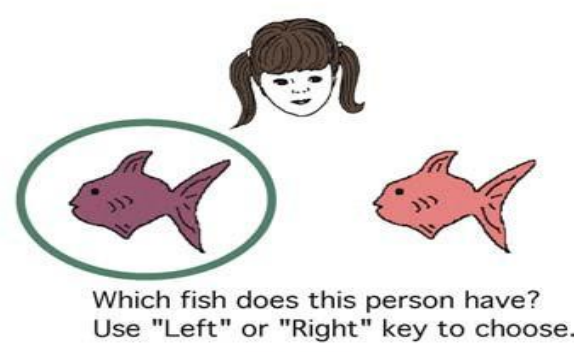

Correct!

Figure 1. Example of an experimental trial. First, stimuli (illustration of a face plus two fishes) appeared on screen. Second, the participant responded, and if it was correct the chosen fish was encircled and confirming feedback was given.

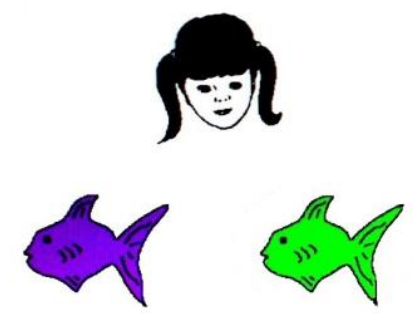

Which fish does this person have? Use "Left" or "Right" key to choose.

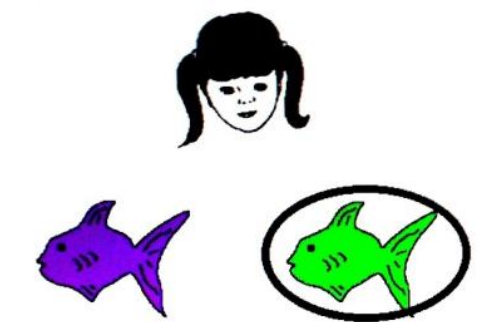

Which fish does this person have? Use "Left" or "Right" key to choose.

\section{Incorrect!}

Figure 2. Examples for incorrect responses: In case the participant gave the wrong answer, the chosen fish was encircled and an incorrect response was given with a sharp, alert beep sound.

The acquisition phase included three stages (Table 3). Stage 1 is named shaping, in which two distinct faces (antecedents) were coupled to different fish (consequent). Stage 2 is the "equivalence training" step, in which two more faces were associated with a fish from the stage 1, while initial conjunctions randomly were reinforced. Stage 3 called 'novel consequents"; the initial faces from stage 1 were associated with new fishes, while the associations from the previous stages were randomly reinforced. Stages 1 and 2 ended after 8 consecutive correct responses, whereas stage 3 terminated after 12 consecutive correct responses. The participant was not warned at the beginning of a new stage. We used these many consecutive correct answers to make sure that the participant successfully gained the increasing number of associations from stage 1 to stage 3. 
After completing the acquisition phase, a second instruction appeared on the screen. This information describes that in the following phase the participant will get identical stimuli but there will be no feedback (correct/ incorrect) given. Information about the appearance of new face-fish associations is not mentioned. ("Good! In this part of the experiment, you will need to remember what you have learned so far. You will NOT be shown the correct answers. At the end of the experiment, the computer will tell you how many you got right. Good luck!")

This is called the transfer phase, because the participant should transfer the previously acquired knowledge. This phase contained 48 trials. Thirty-six trials are old associations learnt during the acquisition phase, but 12 trials are new combinations for testing how s/he can use the learnt situations to solve the novel, untrained settings (in Table 3, only the trials with the new associations are denoted). This required that the participant can recall previously acquired associations and to generalize this knowledge to form new associations. Excluding feedback, participants cannot gain new associations via feedback guided learning, so they have to use the hidden pattern (similarity or equivalence among the combinations) to deal with the test.

Table 3. The acquired equivalence associative learning task

\begin{tabular}{|l|l|l|l|}
\hline \multicolumn{3}{|c|}{ Acquisition Phase } & \multirow{2}{*}{ Transfer Phase: } \\
\cline { 1 - 2 } $\begin{array}{l}\text { Stage 1: } \\
\text { Shaping }\end{array}$ & $\begin{array}{l}\text { Stage 2: } \\
\text { Equivalence training }\end{array}$ & $\begin{array}{l}\text { Stage 3: } \\
\text { New consequences }\end{array}$ & Equivalence testing \\
\hline A1-X1 & A1-X1 & A1-X1 & A2-X2? \\
\hline & A2-X1 & A2-X1 & \\
\hline B1-Y1 & & A1-X2 & B2-Y2 ? \\
\hline & B1-Y1 & B1-Y1 & \\
\hline & B2-Y1 & B2-Y1 & \\
\hline
\end{tabular}

During stage 1, participants learn the first 2 associations between different persons (A, B) and fishes (X, Y). During stage 2, different persons (A2, B2) are associated with the previously seen fish (stimulus equivalence), whereas, during stage 3, new consequences (fish X2, Y2) are added. During the transfer phase, participants are tested on the associations learnt in stages 1-3 (not presented in the table) and also on new associations that are not learnt during stages 1-3, but are the consequences of stimulus equivalence (Myers et al. 2003).

The dependent measures were the average number of errors in the acquisition phase and the proportion of incorrect responses in the transfer phase (for methodological details, see Myers et al. 2003). 


\subsubsection{EXPERIMENT 2: INVESTIGATING THE "THEORY OF MIND” FUNCTION}

Eyes Test

Each participant received the revised version of the Eyes Test in a quiet room. The examiner presented 29 photographs of the eye-region of faces of actors and actresses (Figure 3). Each stimulus was presented on separate cards. Participants were asked to choose which of the four words (one target and three foils) best described the complex mental state of the actor/actress (for example: surprised - joking - sure about something - happy). The four words were depicted on the cards, and the participant read aloud the chosen word. The examiner signed the response on a separate sheet of paper. Each participant was asked to judge the gender of the person shown on the photograph as well. This gender recognition part is used as a control, and normally a ceiling effect can be found (Baron-Cohen et al. 2001). Before the test, subjects were asked to read through a glossary from a separate paper, which contained the meaning of the words describing each mental state. If necessary, participants were allowed to use this glossary paper during the test. The dependent measure was the number of correctly identified mental states from the 29 photographs (for a detailed description, see Baron-Cohen et al. 2001).

\section{Surprised Sure about something}

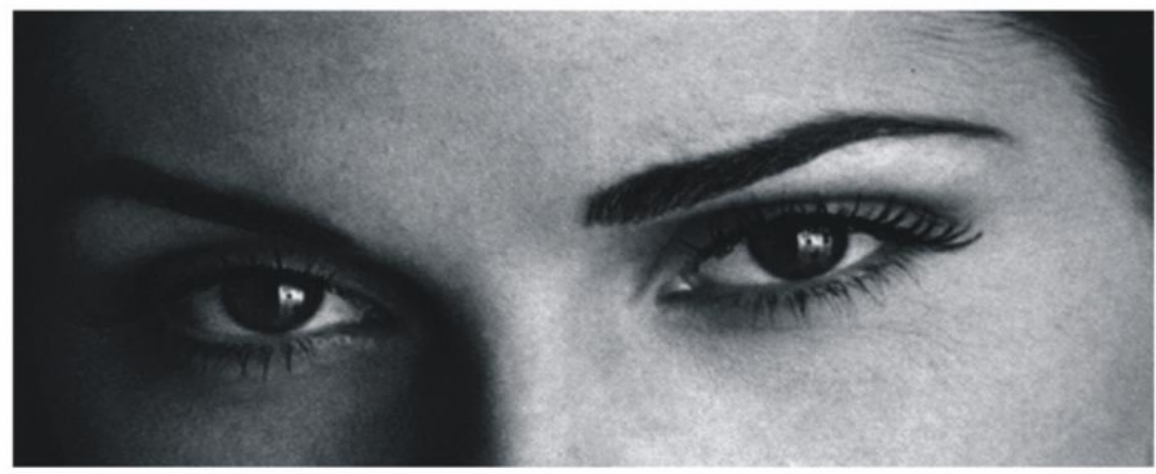

Joking

Happy

Figure 3. An example for stimuli presented during the Baron-Cohen's Eyes Test 


\section{RESULTS}

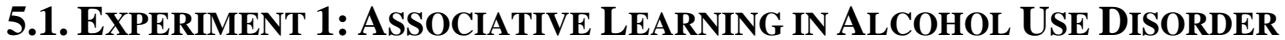

Both phases of the task were completed by all the patients. Regarding the acquisition phase there was no significant difference between patients and controls regarding the mean number of errors (controls: $8.9, \mathrm{SD}=2.3$; patients: $10.1, \mathrm{SD}=2.6 ; \mathrm{t}(38)=1.51, \mathrm{P}=0.14$ ), and the total number of acquisition trials (controls: $35.6, \mathrm{SD}=14.0$; patients: $40.2, \mathrm{SD}=16.7$, $\mathrm{t}(38)=0.94, \mathrm{P}=0.35)$.

Analysis of variance on the proportion of incorrect responses in the transfer phase with the whole group (patients vs. controls) as the between-subjects variable and association type (old vs. new) as the within-subjects variable was calculated. There were significant main effects in the group $(\mathrm{F}(1,38)=27.49, \mathrm{P}<0.001, \eta 2=0.42)$ and association type $(\mathrm{F}(1,38)=$ $37.01, \mathrm{P}<0.001, \eta 2=0.49)$. The interaction between group and association type was also significant $(\mathrm{F}(1,38)=29.65, \mathrm{P}<0.001, \eta 2=0.44)$. Scheffé's post hoc tests expressed that patients had a selective impairment in the case of new associations $(\mathrm{P}<0.001)$ but not in the case of old associations $(\mathrm{P}=0.9)$ (Figure 4$)$.

In addition, we evaluated Pearson's product moment correlation coefficients between test performance (mean errors from the acquisition phase, proportion of incorrect responses for old and new associations in the transfer phase), IQ and BDI scores. Either analysing patient's and control's group together or separately the calculations display no significant results $(-0.2$ $<\mathrm{r}<0.02, \mathrm{P}>0.1)$. 


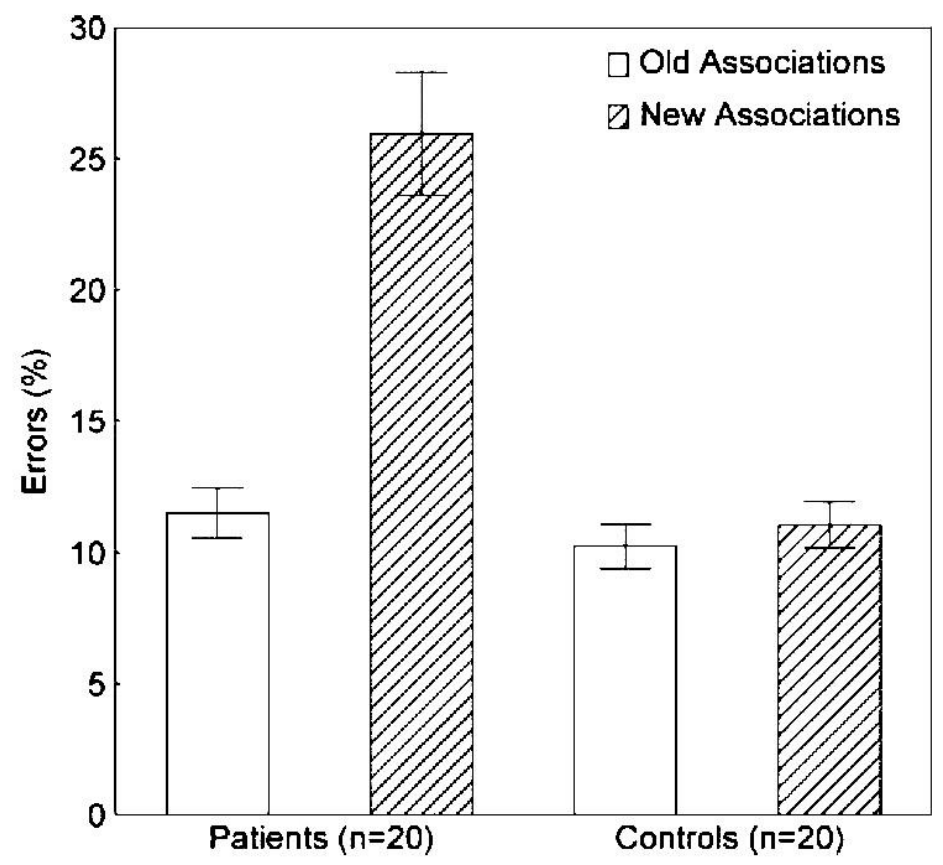

Figure 4. Mean performance in the transfer phase in abstinent patients with alcohol dependence and healthy controls. Error bars indicate standard error of the mean. ${ }^{*} \mathrm{P}<0.001$, Scheffé's test (old vs. new associations in patients).

\subsection{EXPERIMENT 2: “THEORY OF MIND” IN ALCOHOL USE DiSORDER}

Patients with alcoholism and healthy control subjects displayed nearly identical performances on the Eyes Test. The mean value of the correct answers was 22.4/29 (SD: 3.4) for AUD patients, and 22.5/29 (SD: 2.9) for controls. Student's t-tests revealed no significant differences between the two groups $(\mathrm{t}(58)=0.19, \mathrm{P}=0.85)$. Table 4 shows the percentage of patients and controls who chose the correct mental state for each stimulus. Chi-square tests indicated that the distribution of patients and controls who chose the correct target word or one of the foils did not differ significantly $(\mathrm{P}>0.2)$. 
Table 4. Number (percentage) of patients (AUD) and healthy control participants (HC) who chose the correct target description of mental states

\begin{tabular}{|c|c|c|}
\hline Mental State & AUD & $\mathrm{HC}$ \\
\hline Playful & $10(33 \%)$ & $12(40 \%)$ \\
\hline Upset & $16(53 \%)$ & $15(50 \%)$ \\
\hline Desire & $22(73 \%)$ & $21(70 \%)$ \\
\hline Insisting & $24(80 \%)$ & $25(83 \%)$ \\
\hline Worried & $28(93 \%)$ & 27 (90\%) \\
\hline Fantasizing & $21(70 \%)$ & $25(83 \%)$ \\
\hline Uneasy & $25(83 \%)$ & $24(80 \%)$ \\
\hline Despondent & $26(87 \%)$ & $26(87 \%)$ \\
\hline Preoccupied & $17(57 \%)$ & $19(63 \%)$ \\
\hline Cautious & $19(63 \%)$ & $20(67 \%)$ \\
\hline Regretful & $26(87 \%)$ & $27(90 \%)$ \\
\hline Sceptical & $15(50 \%)$ & $13(43 \%)$ \\
\hline Anticipating & $22(73 \%)$ & $21(70 \%)$ \\
\hline Accusing & $19(63 \%)$ & $23(77 \%)$ \\
\hline Contemplative & $23(77 \%)$ & $25(83 \%)$ \\
\hline Thoughtful & $23(77 \%)$ & $23(77 \%)$ \\
\hline Doubtful & $24(80 \%)$ & $26(87 \%)$ \\
\hline Decisive & $27(90 \%)$ & $24(80 \%)$ \\
\hline Tentative & $27(90 \%)$ & $26(87 \%)$ \\
\hline Friendly & $17(57 \%)$ & $19(63 \%)$ \\
\hline Defiant & $27(90 \%)$ & $25(83 \%)$ \\
\hline Pensive & $22(73 \%)$ & $22(73 \%)$ \\
\hline Interested & $25(83 \%)$ & $24(80 \%)$ \\
\hline Hostile & $21(70 \%)$ & $23(77 \%)$ \\
\hline Flirtatious & $19(63 \%)$ & $17(57 \%)$ \\
\hline Distrustful & $11(37 \%)$ & $13(43 \%)$ \\
\hline
\end{tabular}




\section{DISCUSSION}

There are several studies investigating cognitive deficits in AUD patients. Based on the prior data that even following longer periods of abstinence there are existing cognitive impairments. We intended to investigate the social and neurocognitive status in a specially selected AUD population, with quite long term abstinence. We recruited the patients from the local AA group, because it was feasible to enrol drug-free patients with longer periods of confirmed sobriety. On the other hand, at our psychiatric department we apply the Minnesota model in close cooperation with the local AA movement, this connection also contributed to our decision for selection.

In the first part of our investigations we compared the BG and the hippocampal based learning processes in AUD following longer periods of sobriety. Applying a single task with comparably difficult elements we conclude that on the BG dependent stimulus and stimulus associative learning phase patients display no significant underperformance, whereas the hippocampus dependent generalization of this knowledge was severely impaired. These results raise the possibility basal ganglia related processes are spared, but medial temporal lobe functions remain impaired even after intermediate-term abstinence.

In accordance with previous research, the present findings support that several months of sobriety is required for cognitive rehabilitation (Brandt et al. 1983). As it was discussed in the introduction, Fein et al. (1990) in their early review tried to divide the cognitive recovery into 3 stages according to the duration of abstinence: (i) acute detoxification (up to 2 weeks of abstinence), (ii) intermediate period (3 months of abstinence) and (iii) long-term abstinence (from 2 months to 5 years). They emphasize that even in the long-term phase there are some detectable cognitive impairments: especially in abstract reasoning, visuospatial ability, shortterm memory and mental flexibility. Later, Fein et al. (2006) studied a very long-term abstinent group (average abstinence time: 6.7 years) and found that spatial processing was still impaired. Fortunately, other cognitive functions do heal faster (attention and concentration, reaction time, verbal learning, abstract reasoning and verbal short-term memory) (Fein et al., 1990). 
Although the MTL dysfunction in AUD is well known, we have to discuss two further questions (Beresford et al. 2006). Firstly, it is necessary to clarify that in our test design whether transfer generalization impairment could be a consequence of the dysfunction of the prefrontal cortex, and so a part of a wilder executive damage (Bernardin et al. 2014; Pitel et al. 2007). One of the limitations of this study is that unfortunately we did not examine the higher executive processes. Although we have indirect data showing that these functions are independent. Kéri et al. (2005) employed this test in schizophrenia where the prefrontal impairment is known. They found correlation between transfer generalization dysfunctions and hippocampal dependent declarative verbal memory (California Verbal Learning Test) performance but not with the performance on the n-back task (classical working memory test estimating prefrontal functions) (Kéri et al. 2005). These results are against the likelihood that higher level prefrontal pathology would create the transfer generalization dysfunctions.

Secondly we should consider the fact that in other studies using similar tasks, they found unimpaired transfer performance in different substance use disorders. In contrast to our finding, investigations with cocaine (Vadhan et al. 2008), and opiate dependent patients (Myers et al. 2017) showed poor performance on BG dependent and intact performance on MTL dependent activities (Table 5).

Table 5. Comparison of our results with other studies in different SUD

\begin{tabular}{|l|l|l|l|}
\hline & & Acquisition & Transfer \\
\hline Cocaine & Vadhan et al. 2008 & $\downarrow$ & - \\
\hline Opiate & Myers et al. 2017 & $\downarrow$ & - \\
\hline Alcohol & Mattyassy et al. 2012 & - & $\downarrow$ \\
\hline
\end{tabular}

We should mention that Myers et al. (2017) applied a recently updated variant of the acquired equivalence task. In this version reinforcement and punishment strategies were more precisely in focus. One half of the trial types were reward based, and the other half was punishment based. That means in case of reward based learning trials, only the correct responses triggered feedback (“Correct!"; like in Figure 1) and also gained points (+10 as in a token economy system), but incorrect answers received no feedback or points. In case of the punishment based learning, inversely only incorrect responses triggered negative feedback ("Incorrect!" in red) and loss of points $(-10)$. The total points earnt were presented at the bottom of the screen continuously. We should consider that even a slight difference in the test design can manipulate the results. However, this cannot fully explain the difference because 
the result within cocaine population (Vadhan et al. 2008) showed similar pattern as opiate dependent patients.

We should also mention that in our study a special population was selected to exclude the alcohol unrelated influence factors, but obviously they were not representative for the general AUD population. Therefore, the BG related functions could be intact in our sample because contrary to the aforementioned studies we selected patients with longer sobriety periods, and we tried to select populations free of other influencing factors (other drugs, medications, psychiatric disorders etc.). In more serious alcohol cases, we could expect detectable impairment of associative learning. However, it should be pointed out that in their study Virág et al. (2015) found similarly intact BG dependent implicit (sequence) learning in more severe AUD patients with short-term abstinence, which support the fact that alcohol somehow spares this function. Although it is an interesting question for further investigation as to which way alcohol interacts with the brain implicit reward system, if it does not impair the BG dependent learning. This raises the possibility that beside some common features within addictive disorders, the different substances have different influences over particular brain regions.

Conversely, contrary to opiate and cocaine users, the young, well-functioning patients after longer periods of sobriety, without comorbid conditions still exhibited transfer generalization impairments. This suggests that this phase of the associative learning test is highly sensitive for memory impairments in AUD. The special effect of alcohol on the MTL is not a surprise, but it would need further investigation to show why other substances spare this region of the brain.

The most serious limitations of the present study were the small sample size and the fact that we used only a single test for the assessment of memory. The selected patient population we have used could restrict the universality of our results in AUD, but excluding independent factors and selecting patients with longer abstinence period have a huge advantage as well. In the future the follow-up prospective studies could increase the power of the research of this field.

If an impairment exists long after discontinuing substance use, it can be interpreted in two different ways. First, the impairment could refer to a diathesis for addictions, developed before the addiction appeared. In this way we might suppose that damage of the memory 
generalization process can be a vulnerability factor like novelty and sensation seeking, impulsivity, extraversion (Nees et al. 2012; Heinrich et al. 2016; Brumback et al. 2016; Belin et al. 2016) and even alterations in brain oscillations (Porjesz and Rangaswamy 2007; Rangaswamy and Porjesz 2008). However, the probability of this hypothesis is low for addiction disorders in general if we consider the results of other substance disorders. Secondly, based on previous data of MTL impairment in AUD and related animal studies (Fein et al. 1990, 2006; White et al. 2000; Crews and Nixon 2009; Tokuda et al. 2011, Wilson et al. 2017; Liput et al. 2017), we can postulate that toxic effects of alcohol on the human brain persist for a long period of time.

On the other hand, from the therapeutic perspective even if this is a long lasting effect of alcohol, it is probably not a predictor of relapse, assuming that memory generalization dysfunctions were present together with a reasonably good long-term outcome.

Future research should focus on the premorbid cognitive trait markers comparing the toxic consequences. Also it is essential to develop follow-up studies that investigate the gradual effect of abstinence on the rehabilitation of memory generalization and medial temporal lobe functions.

From the social cognitive perspective, we tried to measure the possible deficit using an accepted method in a similarly selected AUD population. In contrast to previous expectations, our results in patients with alcoholism after longer periods of abstinence demonstrate no major impairment in decoding of complex social emotions and complex mental states. Our data do not support the conclusion of the recent meta-analysis which emphasizes that social cognition functions are damaged in AUD. Furthermore, it questions the presumption that disordered social cognition persists for a long period after cessation of alcohol intake. And as a hidden consequence this also questioned the fact that ToM dysfunctions may operate as a diathesis factor in AUD.

The main limitation of the present investigation is that only a single ToM test was applied. Therefore, it is hard to develop a more general conclusion about the social cognitive abilities of patients with alcoholism. The validity and reliability of the test were described in earlier publications (Baron-Cohen et al. 2001; Lawrence et al. 2004; Kelemen et al. 2005; Shaw et al. 2005). Normative scores of healthy participants on the RMET have been 
replicated and validated by several studies. Our earlier investigations confirm an acceptable reliability of RMET (Cronbach's alpha $=0.81)$.

The obtained results contrary to previous findings, and even to our expectations require further explanations. According to the previously discussed meta-analysis, they are mostly based upon studies with recently detoxified patients (Bora and Zorlu 2017; Donadon and Osório 2014; Onuoha et al. 2015). It is not surprising therefore, that immediately after longer periods of alcohol consumption, all types of cognitive impairments are present. In consideration of this we believe our data do not directly contradict the meta-analysis data of the new studies. It is important to treat separately the investigations which include patients with longer durations of abstinence.

Kornreich et al. (2001) used cross-sectional data from patients with alcoholism who were abstinent for at least 2 months and found lower emotion decoding accuracy for anger and disgust. Later the same group (Foisy et al. 2007) designed a follow-up study in which they measured the recognition of the basic emotions at second testing after 3 months of abstinence. Correlating the results to their earlier findings they could not detect significant improvement during this period. The main difference in this respect when comparing it to our studies is that they focused on basic emotions.

Related to higher ToM processes, there is a growing literature using RMET in addiction. In addition, our study, there are only two sources who have investigated long-term abstinence as it was detailed in the meta-analysis (Bora and Zorlu 2017; Onuoha et al. 2015). Bora and Zorlu (2017) in their review mentioned the PhD thesis of Feyza Ersan which uses the RMET task in 29 AUD patients after an average 19 months of abstinence (Ersan F. Comparison in terms neurocognitive functions, impulsivity and theory of mind between alcohol dependence, diagnosed in adults and healthy volunteers. Maltepe University 2014 (Thesis). https://tez.yok.gov.tr/), and found that ToM functions were impaired. The original text is available online in Turkish, but luckily this linguistic challenge was solved within our research team. In the text they describe that the average was 19.4 months of abstinence, with a huge standard deviation (19.4 \pm 30.3 (median:3). There was no other characteristic available according to the abstinence period in the text. ("En uzun bırakma süresi $24.2 \pm 30.5$ (median:11) ay ve testler öncesi ortalama $19.4 \pm 30.3$ (median:3) ay önce alkol almışlardı. Alkolü bıraktıktan en az 1 ay sonar testler uygulanmıştır”, the table of the thesis also 
describes, that the minimum was 1 month, and the maximum was 120 months). According to the available data, this study was not designed for a long-term abstinence population and for that reason the only data certainty was that the patients were not consuming alcohol for a minimum of 1 month. A further question is whether the subjects had any concomitant psychiatric disorders. They exclude the major psychiatric diagnoses but hidden levels of depression were not measured by specific inventories. The study also restricted the information available concerning prescription medications being taken by the subjects (they were selected from a clinical population); the only criteria specified in respect to medication was abstinence of 1 day from benzodiazepine prior to the test being taken. The average of the age of the test subjects was also quite high (46.8 years, $\mathrm{SD}=11.0$; min 16, max 65 years old; in our sample it was 37.6 years $(\mathrm{SD}=11.7))$. The higher male/female ratio (19 males, 10 female) could also affect the result, but it was comparable to our sample ratio (18/12), and can be explained by the fact that AUD has a large gender difference in the average population. In their survey they apply a large number of cognitive tasks: in addition to the Reading Mind in The Eyes Test, they investigated the Wisconsin Card Sorting Test, Balloon Analogue Risk Task, Stop Signal Task, Rey Auditory Verbal Learning Test, Trail Making Test, Visual Reproduction Test on the Wechsler Memory Scale-Revised, Digit Symbol Test, Stroop Task, Auditory Consonant Trigrams Test, Digit Span Test, Controlled Oral Word Association Test, Categorical Verbal Fluency Test. To gain information from different cognitive tests it is extremely important to understand the correlations between the different brain networks, but statistically it requires a much larger sample size, and can also burden the tolerance of the participants, potentially creating a lower level of adherence to the tests. After analysing the basic data, we do not consider that this study represents a comparable source to our long-term abstinence, high functioning population.

A further article is considered important from the point of view of longer abstinent period and is mentioned in both reviews. This is a research conducted by Gizewski et al. (2013) and was designed as a multi-group imaging study comparing the social functions in patients with AUD, with schizophrenia, or with both disorders and healthy controls. They applied an RMET test adapted specifically for fMRI studies. Even though this study was not focussed on the long-term effect of alcohol, the average abstinence period was 1.5 years ( \pm 0.5 years). The 12 AUD patients who were enrolled in the study were drawn from specialised aftercare units. The possible medications of the AUD patients were not detailed, so we may hypothesize they were medication free. The patients of the schizophrenia group obviously received their normal 
prescribed medication. It should be noted that a significant portion of AUD patients had a history of depression $(n=3)$ or anxiety $(n=2)$ disorders. Although the abstinence period was quite long, they also underwent urine tests to rule out any substance misuse in the previous 6 months, and the results showed that the percentage of the polysubstance dependence in their history was fairly high (5 of the 12).

Therefore, from one side it is clear that there are limited data available from long-term abstinent patients, and most of these data have not been derived from studies that were planned to investigate the effect of alcohol cessation, so the predictability error was quite significant. We can conclude that further studies that specifically address this question are essential to extend our understanding and give greater clarity to this puzzle.

It is necessary to mention that we should consider the results from our current patient sample. It is clear that finding a balanced population for any clinical research is a huge challenge. First, we only focused on longer periods of abstinence in order to rule out any direct toxic effects of alcohol. Second, we wanted to rule out any concomitant psychiatric conditions, and related medications. Therefore, we selected our patients outside of the usual clinical setting, and developed a fruitful cooperation with the local AA group. Our sample was characterised unintentionally by relatively late-onset addiction (mean age 37.6 years $(\mathrm{SD}=11.7)$ and duration of the illness 6.2 years $(\mathrm{SD}=4.5))$. This late-onset may also provide a protective factor for cognitive functions either because any vulnerable developmental period is over before the onset of the problematic behaviour, or because the personality characteristic for the later onset may include intrinsic protective traits (or genes). Classically this hypothesis is the foundation of the Cloninger's Type I, Type II typology in AUD. Consequently, if we try to select a proper AUD population excluding any confounding concomitant side factors, we might have selected subjects who were quite similar to normal population, and were very different from the patients suffering with AUD in clinical settings. 


\section{GENERAL DISCUSSION}

\subsection{SUMMARY OF THE RESULTS}

1. After more than 6 months of abstinence, patients with AUD displayed significant deficits in learning quotients when directly compared with the ability to generalize any previously learned associations. This suggests that the medial temporal lobe dependent learning functions are deeply and persistently impaired, so an even longer period of sobriety is needed for regeneration.

2. Patients with AUD display preserved performed stimulus and stimulus associative learning. These results may indicate that although medial temporal lobe functions remain impaired, the basal ganglia-related processes are spared.

3. Using the Eyes Test we could not find ToM deficit in patients, after a longer period of abstinence. Patient and healthy control subjects displayed nearly identical performances on the Eyes Test. This suggests an intact recognition of social emotions and complex mental states in patients with alcoholism after long-term abstinence. 


\subsection{COGNITIVE IMPAIRMENT IN ALCOHOL USE DISORDER}

Cognitive psychology has developed a revolutionary perspective in understanding neuropsychological, neuropsychiatric conditions. In AUD, discovering the vulnerability factors developing this disorder, or participating in relapse could be a huge assistance in creating sophisticated treatments. A crucial question to be asked is whether the identified cognitive impairment is related to the diathesis of addiction, or it is a consequence of longer periods of alcohol misuse? One major approach to help answer this question is to examine the persistence of the impairment during abstinence. Unfortunately, if we survey the available literature, there is limited available material or results that satisfy this demand. Our data supports the possibility that implicit memory, and ToM functions are not candidate trait markers, rather the perceived impairments in other studies are related to the toxic effects of alcohol consumption.

It is contrary to the findings in recently detoxified patients and other SUD populations. Even pure reason, as it was our pre-study hypothesis, would assume, that implicit, reward dependent memory processes, and even more the basic social decoding skills are protective factors against addiction disorders. We must consider that Foisy et al. (2007), in a follow-up study, found that those AUD patients who discontinued their treatment early, displayed much higher cognitive impairments at baseline. Therefore, selecting a population with higher functionality, and longer abstinent duration, we run a high risk of losing those who would be the most vulnerable to relapse.

Additionally, in our study we found that MTL related memory processes are persisting long during abstinence. In all probability, this could well be the result of a long lasting toxic effect of the alcohol, but we could not exclude the premorbid existence of this. However, the importance of this factor in developing addiction, or relapse is questionable, because these patients had been able maintain their sobriety for a long period of time.

Therefore, we can see that no matter how much is it important to take precise information from patient with long-term abstinence, it will provide only a piece to a much more complex puzzle. Although it has a huge advantage in reducing many perplexing variables, it also creates a highly selected population, which may not be representative of the average clinical 
situation. Thus selecting a suitable group from a scientific perspective, we may exclude the most vulnerable patients, and who need the most support in relapse prevention.

We should also consider that a test where more cognitive ToM abilities are required, or even second order ToM functionality requirements, may be more relevant in these populations, although recent meta-analysis does support the usage of this test in AUD.

\subsection{IMPLICATION FOR TREATMENT OF ALCOHOL USE DISORDER}

First of all, we can clearly see, that memory functions related to MTL are persisting long after the cessation of alcohol abuse within high functioning patients. So even more pronounced impairment can be imagined in more severe conditions. It is important to develop either pharmacological treatment strategies (e.g. vitamins, cognitive enhancers) and build this into the early phase of therapy. Other possibilities are to develop cognitive remediation programs directly relating to these patients.

In terms of implicit memory, we could not find significant impairment. That means that there is a spontaneous, rapid regeneration in this area, at least among the higher functioning AUD patients. Although with follow-up studies it would be interesting to investigate if the pharmacotherapy applied for explicit memory regeneration can promote this process as well.

As regards the ToM processes, our results are not supporting the previous findings and the prolonged impairment of them in AUD. Although it is still an important issue, we surmise that some kind of social cognitive attenuation in association with interpersonal complications, should be important in the development of AUD, any possible relapse, or even in discontinuation of treatment (Kornreich et al. 2002; Chung et al. 2001; Litt et al. 2003), so implementing social skills training - especially in the more severe conditions - should generate an additional healing potential. Today different types of social skills trainings are applied in treatment programs developed for addictive patients can enhance the social problem-solving ability of our patients (Eriksen et al. 1986; Litt et al. 2003). Although more effective and specifically tailored training courses could be developed based on the recent research into the relationship between social cognition and interpersonal skills. The results of this research would optimistically be the foundations for evolving new interpersonal training programs in AUD. 
In isolation, it is hard not to recognize that the cognitive markers have limited specificity to a given psychiatric disorder category. Furthermore, we could imagine, that in the future the cognitive profile, or trait dimensions rather than the DSM type diagnostic categories will be the basis of the therapies. This is in line with the suggestions outlined in the RDoC system for experimental studies even today (Lilienfeld and Treadway 2016; Cuthbert and Kozak 2013).

This proposes the possibility that within a given category, there might be different clusters of patients with specific cognitive patterns. Obviously for these different clusters we should develop unique therapeutic strategies, so as to more specifically support individually tailored arrangement rehabilitation programs.

\subsection{FUTURE DIRECTION}

The aims of future studies can be divided into three main areas: (1) Longitudinal followup studies in the field are essential, particularly focusing on the factors important in relapse. (2) Prospective studies using physiologically validated methods in high-risk population (subjects with high genetic and clinical risk for AUD) also may be a major area in future research. (3) Exploring candidate genes that presumably have a role in the development of the brain networks being important in these cognitive abnormalities. 


\section{ACKNOWLEDGEMENTS}

I am indebted to Prof. Dr. Zoltán Janka, Prof. Dr. Szabolcs Kéri, Prof. Dr. Attila Szücs and dr. Oguz Kelemen who provided the possibility to participate in the foregoing research. This work would have not been realized without the work of my colleague Zsuzsanna Sárközi from the alcohol research group. I would like to give my special thanks to all the co-authors of the publications, who all contributed to a large extent to the completion of my thesis: Catherine E. Myers, Einat Levy-Gigi, Mark A. Gluck from the Rutgers University. I would also like to thank the participants of the studies, and specially the patients from the local AA club in their help with this research. Last, but not least, I would like to express my deepest gratitude to my family and friends who have supported me during my $\mathrm{PhD}$ studies and the writing of my dissertation. 


\section{REFERENCES}

1. American Psychiatric Association (1994) Diagnostic and Statistical Manual of Mental Disorders, 4th edn. (DSM-IV) APA Press, Washington, DC.

2. Ames SL, Stacy AW. (1998) Implicit cognition in the prediction of substance use among drug offenders. Psychol Addict Behav. 12:1-10.

3. Andó B, Must A, Kurgyis E, Szkaliczki A, Drótos G, Rózsa S, Szikszay P, Horváth S, Janka Z, Álmos PZ. (2012) Personality traits and coping compensate for disadvantageous decision-making in long-term alcohol abstinence. Alcohol Alcohol. 47(1):18-24.

4. Ashby FG, Alfonso-Reese LA, Turken AU, Waldron EM. (1998) A neuropsychological theory of multiple systems in category learning. Psychol Rev. 105(3):442-481.

5. Balázs J, Bitter I. (2000) Study on construct validity of the M.I.N.I. PLUS interview. Psychiat Hung. 15:134-144.

6. Baron-Cohen S, Wheelwright S, Hill J, Raste Y, Plumb I. (2001) The "Reading the Mind in the Eyes" Test revised version: a study with normal adults, and adults with Asperger syndrome or high-functioning autism. J Child Psychol Psychiat. 42:241-251.

7. Baron-Cohen S, Ring HA, Wheelwright S, Bullmore ET, Brammer MJ, Simmons A, Williams SC. (1999) Social intelligence in the normal and autistic brain: an fMRI study. Eur J Neurosci. 11(6):1891-1898.

8. Beck AT. (1987) Beck depression inventory. The Psychological Corporation, San Antonio, TX. 
9. Belin D, Belin-Rauscent A, Everitt BJ, Dalley JW. (2016) In search of predictive endophenotypes in addiction: insights from preclinical research. Genes Brain Behav. 15(1):74-88.

10. Berens SC, Bird CM. (2017) The role of the hippocampus in generalizing configural relationships. Hippocampus. 27(3):223-228.

11. Beresford TP, Arciniegas DB, Alfers J, Clapp L, Martin B, Du Y, Liu D, Shen D, Davatzikos C. (2006). Hippocampus volume loss due to chronic heavy drinking. Alcohol Clin Exp Res. 30:1866-1870.

12. Bernardin F, Maheut-Bosser A, Paille F. (2014) Cognitive impairments in alcoholdependent subjects. Front Psychiatry. 16; 5:78.

13. Bickel WK, Moody LN, Eddy CR, Franck CT. (2017) Neurocognitive dysfunction in addiction: Testing hypotheses of diffuse versus selective phenotypic dysfunction with a classification-based approach. Exp Clin Psychopharmacol. 25(4):322-332.

14. Bódi N, Csibri E, Myers CE, Gluck MA, Kéri S. (2009) Associative learning, acquired equivalence, and flexible generalization of knowledge in mild Alzheimer disease. Cogn Behav Neurol. 22(2):89-94.

15. Bora E, Bartholomeusz C, Pantelis C. (2016) Meta-analysis of Theory of Mind (ToM) impairment in bipolar disorder. Psychol Med. 46(2):253-264.

16. Bora E, Berk M. (2016) Theory of mind in major depressive disorder: A meta-analysis. J Affect Disord. 191:49-55.

17. Bora E, Pantelis C. (2016a) Meta-analysis of social cognition in attentiondeficit/hyperactivity disorder (ADHD): comparison with healthy controls and autistic spectrum disorder. Psychol Med. 46(4):699-716.

18. Bora E, Pantelis C. (2016b) Social cognition in schizophrenia in comparison to bipolar disorder: A meta-analysis. Schizophr Res. 175(1-3):72-78. 
19. Bora E, Zorlu N. (2017) Social cognition in alcohol use disorder: a meta-analysis. Addiction. 112(1):40-48.

20. Brandt J, Butters N, Ryan C, Bayog R. (1983) Cognitive loss and recovery in long-term alcohol abusers. Arch Gen Psychiatry. 40:435-442.

21. Brumback TY, Worley M, Nguyen-Louie TT, Squeglia LM, Jacobus J, Tapert SF. (2016) Neural predictors of alcohol use and psychopathology symptoms in adolescents. Dev Psychopathol. 28(4pt1):1209-1216.

22. Bull R, Phillips LH, Conway CA. (2008) The role of control functions in mentalizing: dual-task studies of theory of mind and executive function. Cognition. 107(2):663-672.

23. Butterworth RF. (1995) Pathophysiology of alcoholic brain damage: synergistic effects of ethanol, thiamine deficiency and alcoholic liver disease. Metab Brain Dis. 10(1):1-8.

24. Carrico AW, Gifford EV, Moos RH. (2007) Spirituality/religiosity promotes acceptance-based responding and 12-step involvement. Drug Alcohol Depend. 89(1):66-73.

25. Chanraud S, Pitel AL, Müller-Oehring EM, Pfefferbaum A, Sullivan EV. (2013) Remapping the brain to compensate for impairment in recovering alcoholics. Cereb Cortex. 23(1):97-104.

26. Chanraud S, Sullivan EV. (2014) Compensatory recruitment of neural resources in chronic alcoholism. Handb Clin Neurol. 125:369-380.

27. Chung T, Langenbucher J, Labouvie E, Pandina RJ, Moos RH. (2001) Changes in alcoholic patients' coping responses predict 12-month treatment outcomes. J Consult Clin Psychol. 69(1):92-100.

28. Crews FT, Nixon K. (2009) Mechanisms of neurodegeneration and regeneration in alcoholism. Alcohol Alcohol. 44:115-127. 
29. Cuthbert BN, Kozak MJ. (2013) Constructing constructs for psychopathology: the NIMH research domain criteria. J Abnorm Psychol. 122(3):928-937.

30. Dalili MN, Penton-Voak IS, Harmer CJ, Munafò MR. (2015) Meta-analysis of emotion recognition deficits in major depressive disorder. Psychol Med. 45(6):1135-1144.

31. Donadon MF, Osório FL. (2014) Recognition of facial expressions by alcoholic patients: a systematic literature review. Neuropsychiatr Dis Treat. 10:1655-1663.

32. Duka T, Weissenborn R, Dienes Z. (2001) State-dependent effects of alcohol on recollective experience, familiarity and awareness of memories. Psychopharmacology (Berl.) 153(3):295-306.

33. Eriksen L, Björnstad S, Götestam KG. (1986) Social skills training in groups for alcoholics: one-year treatment outcome for groups and individuals. Addict Behav. 11(3):309-329.

34. Ersan F. (2014) Comparison with in terms neurocognitive functions, impulsivity and theory of mind between alcohol dependence diagnosed adults and healthy volunteers. Maltepe University (Thesis). Available at: https://tez.yok.gov.tr/

35. Ewing JA. (1984) Detecting alcoholism. The CAGE questionnaire. J Am Med Assoc. 252:1905-1907.

36. Fama R, Pfefferbaum A, Sullivan EV. (2006) Visuoperceptual learning in alcoholic Korsakoff syndrome. Alcohol Clin Exp Res. 30(4):680-687.

37. Fein G, Bachman L, Fisher S, Davenport L. (1990) Cognitive impairments in abstinent alcoholics. West J Med. 152(5):531-537.

38. Fein G, Torres J, Price LJ, Di Sclafani V. (2006) Cognitive performance in long-term abstinent alcoholic individuals. Alcohol Clin Exp Res. 30(9):1538-1544. 
46

39. Fernández-Serrano MJ, Pérez-García M, Schmidt Río-Valle J, Verdejo-García A. (2010) Neuropsychological consequences of alcohol and drug abuse on different components of executive functions. J Psychopharmacol. 24(9):1317-1332.

40. Fine C, Lumsden J, Blair R. (2001) Dissociation between theory of mind and executive functions in a person with early left amygdala damage. Brain. 124:287-298.

41. Foisy ML, Kornreich C, Fobe A, D'Hondt L, Pelc I, Hanak C, Verbanck P, Philippot P. (2007) Impaired emotional facial expression recognition in alcohol dependence: do these deficits persist with midterm abstinence? Alcohol Clin Exp Res. 31(3):404-410.

42. Frings D, Moss AC, Albery IP, Eskisan G, Wilcockson TD, Marchant AP. (2018) Environmental context influences visual attention to responsible drinking messages. Alcohol Alcohol. 53(1):46-51.

43. Frith CD, Frith U. (1999) Interacting minds - a biological basis. Science. 286:16921695.

44. Frith U, Morton J, Leslie AM. (1991) The cognitive basis of a biological disorder: autism. Trends Neurosci. 14(10):433-438.

45. Gabrieli JD. (1998) Cognitive neuroscience of human memory. Annu Rev Psychol. 49: $87-115$.

46. Gallagher H. L., Frith C. D. (2003) Functional imaging of 'theory of mind'. Trends Cogn Sci. 7:77-83.

47. Gizewski ER, Müller BW, Scherbaum N, Lieb B, Forsting M, Wiltfang J, Leygraf N, Schiffer B. (2013) The impact of alcohol dependence on social brain function. Addict Biol. 18:109-120.

48. Gottesman II, Gould TD. (2003) The endophenotype concept in psychiatry: etymology and strategic intentions. Am J Psychiatry. 160(4):636-645. 
49. Gould TD, Gottesman II. (2006) Psychiatric endophenotypes and the development of valid animal models. Genes Brain Behav. 5(2):113-119.

50. Graybiel AM. (2008) Habits, rituals, and the evaluative brain. Annu Rev Neurosci. 31:359-387.

51. Hatchard T, Smith AM, Halchuk RE, Longo CA, Fried PA, Hogan MJ, Cameron I. (2015) Effects of low-level alcohol use on cognitive interference: an fMRI study in young adults. Alcohol. 49(1):7-13.

52. Healey KM, Bartholomeusz CF, Penn DL. (2016) Deficits in social cognition in first episode psychosis: A review of the literature. Clin Psychol Rev. 50:108-137.

53. Heinrich A, Müller KU, Banaschewski T, Barker GJ, Bokde ALW, Bromberg U, Büchel C, Conrod P, Fauth-Bühler M, Papadopoulos D, Gallinat J, Garavan H, Gowland P, Heinz A, Ittermann B, Mann K, Martinot JL, Paus T, Pausova Z, Smolka M, Ströhle A, Rietschel M, Flor H, Schumann G, Nees F; IMAGEN consortium. (2016) Prediction of alcohol drinking in adolescents: Personality-traits, behavior, brain responses, and genetic variations in the context of reward sensitivity. Biol Psychol. 118:79-87.

54. Hill SY, Kostelnik B, Holmes B, Goradia D, McDermott M, Diwadkar V, Keshavan M. (2007) fMRI BOLD response to the eyes task in offspring from multiplex alcohol dependence families. Alcohol Clin Exp Res. 31(12):2028-2035.

55. Hulvershorn LA, Finn P, Hummer TA, Leibenluft E, Ball B, Gichina V, Anand A. (2013) Cortical activation deficits during facial emotion processing in youth at high risk for the development of substance use disorders. Drug Alcohol Depend. 131(3):230-237.

56. Kelemen O, Erdélyi R, Pataki I, Benedek G, Janka Z, Kéri S. (2005) Theory of mind and motion perception in schizophrenia. Neuropsychology 19:494-500. 
57. Kéri S, Nagy O, Kelemen O, Myers CE, Gluck MA. (2005) Dissociation between medial temporal lobe and basal ganglia memory systems in schizophrenia. Schizophr Res. 15; 77(2-3):321-318.

58. Kéri S. (2003) The cognitive neuroscience of category learning. Brain Res Brain Res Rev. 43:85-109.

59. Koob GF, Volkow ND. (2016) Neurobiology of addiction: a neurocircuitry analysis. Lancet Psychiatry. 3(8):760-773.

60. Kopera M, Glass JM, Heitzeg MM, Wojnar M, Puttler LI, Zucker RA. (2014) Theory of mind among young adult children from alcoholic families. J Stud Alcohol Drugs. 75(5):889-894.

61. Kopera M, Glass JM, Heitzeg MM, Wojnar M, Puttler LI, Zucker RA. (2014) Theory of mind among young adult children from alcoholic families. J Stud Alcohol Drugs 75(5):889-894.

62. Korkmaz B. (2011). "Theory of mind and neurodevelopmental disorders of childhood". Pediatr. Res. 69 (5 Pt 2):101R-108R

63. Kornreich C, Blairy S, Philippot P, Hess U, Noël X, Streel E, Le Bon O, Dan B, Pelc I, Verbanck P. (2001) Deficits in recognition of emotional facial expression are still present in alcoholics after mid- to long-term abstinence. J Stud Alcohol. 62(4):533-542.

64. Kornreich C, Philippot P, Foisy ML, Blairy S, Raynaud E, Dan B, Hess U, Noël X, Pelc I, Verbanck P. (2002) Impaired emotional facial expression recognition is associated with interpersonal problems in alcoholism. Alcohol Alcohol. 37(4):394-400.

65. Kornreich C, Saeremans M, Delwarte J, Noël X, Campanella S, Verbanck P, Ermer E, Brevers D. (2016) Impaired non-verbal emotion processing in pathological gamblers. Psychiatry Res. 236:125-129. 
66. Kornreich C, Foisy ML, Philippot P, Dan B, Tecco J, Noël X, Hess U, Pelc I, Verbanck P. (2003) Impaired emotional facial expression recognition in alcoholics, opiate dependence subjects, methadone maintained subjects and mixed alcohol-opiate antecedents subjects compared with normal controls. Psychiat Res. 119:251-260.

67. Kostek JA, Beck KD, Gilbertson MW, Orr SP, Pang KC, Servatius RJ, Myers CE. (2014) Acquired equivalence in US veterans with symptoms of posttraumatic stress: Reexperiencing symptoms are associated with greater generalization. J Traumat Stress. 27(6):717-720.

68. Lachenmeier DW, Taylor BJ, Rehm J. (2011) Alcohol under the radar: do we have policy options regarding unrecorded alcohol? Int J Drug Policy. 22(2):153-160.

69. Lawrence EJ, Shaw P, Baker D, Baron-Cohen S, David AS. (2004) Measuring empathy: reliability and validity of the Empathy Quotient. Psychol Med. 34(5):911-919.

70. Le Berre AP, Fama R, Sullivan EV. (2017) Executive functions, memory, and social cognitive deficits and recovery in chronic alcoholism: A critical review to inform future research. Alcohol Clin Exp Res. 41(8):1432-1443.

71. Le Berre AP, Pinon K, Vabret F, Pitel AL, Allain P, Eustache F, Beaunieux H. (2010) Study of metamemory in patients with chronic alcoholism using a feeling-of-knowing episodic memory task. Alcohol Clin Exp Res. 34(11):1888-1898.

72. Levy-Gigi E, Szabo C, Richter-Levin G, Kéri S. (2015) Reduced hippocampal volume is associated with overgeneralization of negative context in individuals with PTSD. Neuropsychology 29(1):151-161.

73. Lilienfeld SO, Treadway MT. (2016) Clashing diagnostic approaches: DSM-ICD versus RDoC. Annu Rev Clin Psychol. 12:435-463.

74. Ling J, Stephens R, Heffernan TM. (2010) Cognitive and psychomotor performance during alcohol hangover. Curr Drug Abuse Rev. 3(2):80-87. 
75. Liput DJ, Pauly JR, Stinchcomb AL, Nixon K. (2017) Binge alcohol exposure transiently changes the endocannabinoid system: A potential target to prevent alcoholinduced neurodegeneration. Brain Sci. 29; 7(12). pii: E158.

76. Litt MD, Kadden RM, Cooney NL, Kabela E. (2003) Coping skills and treatment outcomes in cognitive-behavioral and interactional group therapy for alcoholism. $\mathbf{J}$ Consult Clin Psychol. 71(1):118-128.

77. Loheswaran G, Barr MS, Rajji TK, Blumberger DM, Le Foll B, Daskalakis ZJ. (2016) Alcohol intoxication by binge drinking impairs neuroplasticity. Brain Stimul. 9(1):2732.

78. Lovinger DM, Alvarez VA. (2017) Alcohol and basal ganglia circuitry: Animal models. Neuropharmacology 122:46-55.

79. Manns JR, Eichenbaum H. (2006) Evolution of declarative memory. Hippocampus 16(9):795-808.

80. Marceau EM, Berry J, Lunn J, Kelly PJ, Solowij N. (2017) Cognitive remediation improves executive functions, self-regulation and quality of life in residents of a substance use disorder therapeutic community. Drug Alcohol Depend. 178:150-158.

81. Martin PR, Adinoff B, Weingartner H, Mukherjee AB, Eckardt MJ. (1986) Alcoholic organic brain disease: nosology and pathophysiologic mechanisms. Prog Neuropsychopharmacol Biol Psychiatry. 10(2):147-164.

82. McKinney A, Coyle K. (2004) Next day effects of a normal night's drinking on memory and psychomotor performance. Alcohol Alcohol. 39(6):509-513.

83. McLellan AT, Luborsky L, Woody GE, O'Brien CP. (1980) An improved diagnostic evaluation instrument for substance abuse patients. The Addiction Severity Index. J Nerv Ment Dis. 168(1):26-33. 
84. Mishkin M, Malamut B, Bachevalier J. (1984) Memories and habits: two neural systems. In: McGaugh, J., Lynch, G., Weinberg, N. (Eds.), The Neurobiology of Learning and Memory. Guilford Press, New York, NY, pp. 65-77.

85. Molenberghs P, Johnson H, Henry JD, Mattingley JB. (2016) Understanding the minds of others: A neuroimaging meta-analysis. Neurosci Biobehav Rev. 65:276-291.

86. Mondragón-Maya A, Ramos-Mastache D, Roman PD, Yáñez-Téllez G. (2017) Social cognition in schizophrenia, unaffected relatives and ultra-high risk for psychosis: What do we currently know? Actas Esp Psiquiatr. 45(5):218-226.

87. Monnot M, Nixon S, Lovallo W, Ross E. (2001) Altered emotional perception in alcoholics: deficits in affective prosody comprehension. Alcohol Clin Exp Res. 25:362369.

88. Moustafa AA, Kéri S, Herzallah MM, Myers CE, Gluck MA. (2010) A neural model of hippocampal-striatal interactions in associative learning and transfer generalization in various neurological and psychiatric patients. Brain Cogn. 74(2):132-144.

89. Myers CE, Rego J, Haber P, Morley K, Beck KD, Hogarth L, Moustafa AA. (2017) Learning and generalization from reward and punishment in opioid addiction Behav Brain Res. 317:122-131.

90. Myers CE, Kluger A, Golomb J, Ferris S, de Leon MJ, Schnirman G, Gluck MA. (2002) Hippocampal atrophy disrupts transfer generalization in nondemented elderly. J Geriatr Psychiatry Neurol. 15:82-90.

91. Myers CE, Shohamy D, Gluck MA, Grossman S, Kluger A, Ferris S, Golomb J, Schnirman G, Schwartz R. (2003) Dissociating hippocampal versus basal ganglia contributions to learning and transfer. J Cogn Neurosci. 15(2):185-193.

92. Nandrino JL, El Haj M, Torre J, Naye D, Douchet H, Danel T, Cottençin O. (2016) Autobiographical memory deficits in alcohol-dependent patients with short- and longterm abstinence. Alcohol Clin Exp Res. 40(4):865-873. 
93. Nandrino JL, Gandolphe MC, Alexandre C, Kmiecik E, Yguel J, Urso L. (2014) Cognitive and affective theory of mind abilities in alcohol-dependent patients: the role of autobiographical memory. Drug Alcohol Depend. 143:65-73.

94. Nees F, Tzschoppe J, Patrick CJ, Vollstädt-Klein S, Steiner S, Poustka L, Banaschewski T, Barker GJ, Büchel C, Conrod PJ, Garavan H, Heinz A, Gallinat J, Lathrop M, Mann K, Artiges E, Paus T, Poline JB, Robbins TW, Rietschel M, Smolka MN, Spanagel R, Struve M, Loth E, Schumann G, Flor H; IMAGEN Consortium. (2012) Determinants of early alcohol use in healthy adolescents: the differential contribution of neuroimaging and psychological factors. Neuropsychopharmacology 37:986-995.

95. Németh VL, Kurgyis E, Csifcsák G, Maráz A, Almási DA, Drótos G, Szikszay P, Andó B, Janka Z, Must A. (2014) The impact of intermediate-term alcohol abstinence on memory retrieval and suppression. Front Psychology. 2; 5:1396.

96. Onuoha RC, Quintana DS, Lyvers M, Guastella AJ. (2016) A meta-analysis of theory of mind in alcohol use disorders. Alcohol Alcohol. 51(4):410-415.

97. Oscar-Berman M, Marinkovic K. (2003). Alcoholism and the brain: an overview. Alcohol Res Health. 27:125-133.

98. Oscar-Berman M, Marinković K. (2007) Alcohol: effects on neurobehavioral functions and the brain. Neuropsychol Rev. 17(3):239-257.

99. Oscar-Berman M, Shagrin B, Evert DL, Epstein C. (1997) Impairments of brain and behavior: the neurological effects of alcohol. Alcohol Health Res World. 21(1):65-75.

100. Oudman E, Van der Stigchel S, Wester AJ, Kessels RP, Postma A. (2011) Intact memory for implicit contextual information in Korsakoff's amnesia. Neuropsychologia 49:2848-2855 
101. Overgaauw S, van Duijvenvoorde AC, Gunther Moor B, Crone EA. (2015) A longitudinal analysis of neural regions involved in reading the mind in the eyes. Soc Cogn Affect Neurosci. 10(5):619-627.

102. Packard MG, Knowlton BJ. (2002) Learning and memory functions of the basal ganglia. Annu Rev Neurosci. 25:563-593.

103. Park MS, Sohn JH, Suk JA, Kim SH, Sohn S, Sparacio R. (2007) Brain substrates of craving to alcohol cues in subjects with alcohol use disorder. Alcohol Alcohol. 42:417422.

104. Pelphrey KA, Shultz S, Hudac CM, Vander Wyk BC. (2011) Research review: Constraining heterogeneity: the social brain and its development in autism spectrum disorder. J Child Psychol Psychiatry. 52(6):631-644.

105. Penn DL, Corrigan PW, Bentall RP, Racenstein JM, Newman L. (1997) Social cognition in schizophrenia. Psychol Bull. 121:114-132.

106. Peters GJ, Kok G, Abraham C. (2008) Social cognitive determinants of ecstasy use to target in evidence-based interventions: a meta-analytical review. Addiction. 103(1):109118.

107. Pfefferbaum A, Rosenbloom M, Rohlfing T, Sullivan EV. (2009) Degradation of association and projection white matter systems in alcoholism detected with quantitative fiber tracking. Biol Psychiatry. 65(8):680-690.

108. Pitel AL, Eustache F, Beaunieux H. (2014) Component processes of memory in alcoholism: pattern of compromise and neural substrates. Handb Clin Neurol. 125:211225.

109. Pitel AL, Witkowski T, Vabret F, Guillery-Girard B, Desgranges B, Eustache F, Beaunieux H. (2007) Effect of episodic and working memory impairments on semantic and cognitive procedural learning at alcohol treatment entry. Alcohol Clin Exp Res. 31(2):238-248. 
110. Poldrack RA, Packard MG. (2003) Competition among multiple memory systems: converging evidence from animal and human brain studies. Neuropsychologia. 41:245251.

111. Poletti M, Enrici I, Adenzato M. (2012) Cognitive and affective Theory of Mind in neurodegenerative diseases: neuropsychological, neuroanatomical and neurochemical levels. Neurosci Biobehav Rev. 36(9):2147-2164.

112. Porjesz B, Rangaswamy M. (2007) Neurophysiological endophenotypes, CNS disinhibition, and risk for alcohol dependence and related disorders. Sci World J. 7:131141.

113. Prat G, Adan A, Pérez-Pàmies M, Sànchez-Turet M. (2008) Neurocognitive effects of alcohol hangover. Addict Behav. 33(1):15-23.

114. Rajkumar AP, Yovan S, Raveendran AL, Russell PS. (2008) Can only intelligent children do mind reading: the relationship between intelligence and theory of mind in 8 to 11 years old. Behav Brain Funct. 4:51.

115. Rangaswamy M, Porjesz B. (2008) Uncovering genes for cognitive (dys)function and predisposition for alcoholism spectrum disorders: a review of human brain oscillations as effective endophenotypes. Brain Res. 1235:153-171.

116. Rehm J, Taylor B, Mohapatra S, Irving H, Baliunas D, Patra J, Roerecke M. (2010) Alcohol as a risk factor for liver cirrhosis: a systematic review and meta-analysis. Drug Alcohol Rev. 29(4):437-445.

117. Reich RR, Below MC, Goldman MS. (2010) Explicit and implicit measures of expectancy and related alcohol cognitions: a meta-analytic comparison. Psychol Addict Behav. 24(1):13-25.

118. Roehrich L, Goldman MS. (1995). Implicit priming of alcohol expectancy memory processes and subsequent drinking behavior. Exp Clin Psychopharmacol. 3(4):402-410. 
119. Sacks JJ, Gonzales KR, Bouchery EE, Tomedi LE, Brewer RD. (2015) 2010 National and State Costs of Excessive Alcohol Consumption. Am J Prev Med. 49(5):e73-e79.

120. Samamé C, Martino DJ, Strejilevich SA. (2012) Social cognition in euthymic bipolar disorder: systematic review and meta-analytic approach. Acta Psychiatr Scand. 125(4):266-280.

121. SAMHSA: Substance Abuse and Mental Health Services Administration. (2015) National Survey on Drug Use and Health (NSDUH). Table 5.6A-Substance Use Disorder in Past Year among Persons Aged 18 or Older, by Demographic Characteristics: Numbers in Thousands, 2014 and 2015. Available at: https://www.samhsa.gov/data/sites/default/files/NSDUH-DetTabs-2015/NSDUHDetTabs-2015/NSDUH-DetTabs-2015.htm\#tab5-6a. Accessed 9/27/2018.

122. Sanvicente-Vieira B, Kluwe-Schiavon B, Corcoran R, Grassi-Oliveira R. (2017). Theory of Mind impairments in women with cocaine addiction". J Stud Alcohol Drugs. 78 (2):258-267.

123. Sanvicente-Vieira B, Romani-Sponchiado A, Kluwe-Schiavon B, Brietzke E, Araujo RB, Grassi-Oliveira R. (2017) Theory of Mind in substance users: A systematic minireview. Subst Use Misuse. 52(1):127-133.

124. Schacter DL, Wagner AD, Buckner RL. (2000) Memory systems of 1999. In: Tulving E., Craik FIM. (Eds.), The Oxford Handbook of Memory. Oxford University Press, Oxford, pp. 627-643.

125. Schulte T, Mũller-Oehring EM, Pfefferbaum A, Sullivan EV. (2010) Neurocircuitry of emotion and cognition in alcoholism: contributions from white matter fiber tractography. Dialogues Clin Neurosci. 12(4):554-560.

126. Shamay-Tsoory SG, Aharon-Peretz J, Perry D. (2009) Two systems for empathy: A double dissociation between emotional and cognitive empathy in inferior frontal gyrus versus ventromedial prefrontal lesions. Brain 132:617-627. 
127. Shamay-Tsoory SG, Aharon-Peretz J. (2007) Dissociable prefrontal networks for cognitive and affective theory of mind: a lesion study. Neuropsychologia. 45:30543067.

128. Shaw P, Bramham J, Lawrence EJ, Morris R, Baron-Cohen S, David AS. (2005) Differential effects of lesions of the amygdala and prefrontal cortex on recognizing facial expressions of complex emotions. J Cogn Neurosci. 17(9):1410-1419.

129. Sheehan DV, Lecrubier Y, Sheehan KH, Amorim P, Janavs J, Weiller E, Hergueta T, Baker R, Dunbar GC. (1998) The Mini-International Neuropsychiatric Interview (M.I.N.I.): the development and validation of a structured diagnostic psychiatric interview for DSM-IV and ICD-10. J Clin Psychiatry. 59 (Suppl. 20):22-33.

130. Shohamy D, Wagner AD. (2008) Integrating memories in the human brain: hippocampal-midbrain encoding of overlapping events. Neuron. 60:378-389.

131. Squire LR. (2004) Memory systems of the brain: a brief history and current perspective. Neurobiol Learn Mem. 82:171-177.

132. Tokuda K, Izumi Y, Zorumski CF. (2011) Ethanol enhances neurosteroidogenesis in hippocampal pyramidal neurons by paradoxical NMDA receptor activation. J Neurosci. 31:9905-9909.

133. Uekermann J, Daum I. (2008). "Social cognition in alcoholism: a link to prefrontal cortex dysfunction?". Addiction. 103 (5):726-735.

134. Vadhan NP, Myers CE, Rubin E, Shohamy D, Foltin RW, Gluck MA. (2008) Stimulusresponse learning in long-term cocaine users: acquired equivalence and probabilistic category learning. Drug Alcohol Depend. 11; 93(1-2):155-162.

135. van Holst RJ, Schilt T. (2011) Drug-related decrease in neuropsychological functions of abstinent drug users. Curr Drug Abuse Rev. 4(1):42-56. 
136. Verhulst B, Neale MC, Kendler KS. (2015) The heritability of alcohol use disorders: a meta-analysis of twin and adoption studies. Psychol Med. 45(5):1061-1072.

137. Vinader-Caerols C, Talk A, Montañés A, Duque A, Monleón S. (2017) Differential Effects of alcohol on memory performance in adolescent men and women with a binge drinking history. Alcohol Alcohol. 52(5):610-616.

138. Virág M, Janacsek K, Horváth A, Bujdosó Z, Fabó D, Németh D. (2015) Competition between frontal lobe functions and implicit sequence learning: evidence from the longterm effects of alcohol. Exp Brain Res. 233(7):2081-2089.

139. Wechsler, D. (1981) Wechsler Adult Intelligence Scale-Revised Manual. Psychological Corporation, New York.

140. Weingardt K, Stacy AW, Leigh BC. (1996) Automatic activation of alcohol concepts in response to positive outcomes of alcohol use. Alcohol Clin Exp Res. 20: 25-30.

141. White AM, Matthews DB, Best PJ. (2000) Ethanol, memory and hippocampal function. Hippocampus. 10:88-93.

142. Wiers RW, Stacy AW, Ames SL, Noll JA, Sayette MA, Zack M, Krank M. (2002) Implicit and explicit alcohol-related cognitions. Alcohol Clin Exp Res. 26(1):129-137.

143. Wilson S, Bair JL, Thomas KM, Iacono WG. (2017) Problematic alcohol use and reduced hippocampal volume: a meta-analytic review. Psychol Med. 47(13):2288-2301.

144. World Health Organization (WHO) (2017). Global Status Report on Alcohol and Health. p. XIV. 2014 ed. Available at: http://www.who.int/substance_abuse/publications/global_alcohol_report/msb_gsr_2014 _1.pdf?ua=1. Accessed 9/27/2018.

145. Yang DY, Rosenblau G, Keifer C, Pelphrey KA. (2015) An integrative neural model of social perception, action observation, and theory of mind. Neurosci Biobehav Rev. 51:263-275. 
146. Yin HH, Knowlton BJ. (2006) The role of the basal ganglia in habit formation. Nat Rev Neurosci. 7(6):464-476.

147. Zola-Morgan S, Squire LR. (1993) Neuroanatomy of memory. Annu Rev Neurosci. 3; 16:547-563. 